\title{
Extracts from Hericium erinaceus relieve inflammatory bowel disease by regulating immunity and gut microbiota
}

\author{
Chen Diling ${ }^{1, *}$, Yang Xinn ${ }^{2, *}$, Zheng Chaoqun ${ }^{1}$, Yang Jian ${ }^{1}$, Tang Xiaocui ${ }^{1}$, Chen Jun ${ }^{3}$, \\ Shuai Ou ${ }^{1,4}$ and Xie Yizhen ${ }^{1,4}$ \\ ${ }^{1}$ State Key Laboratory of Applied Microbiology Southern China, Guangdong Provincial Key Laboratory of Microbial Culture \\ Collection and Application, Guangdong Open Laboratory of Applied Microbiology, Guangdong Institute of Microbiology, \\ Guangzhou 510070, China \\ ${ }^{2}$ Department of Pharmacy, The Fifth Affiliated Hospital of Guangzhou Medical University, Guangzhou 510700, China \\ ${ }^{3}$ Departerment of Infertility and Sexual Medicine, The Third Affiliated Hospital of Sun Yat-sen University, Guangzhou 510631, \\ China \\ ${ }^{4}$ Guangdong Yuewei Edible Fungi Technology Co. Ltd, Guangzhou 510070, China \\ *These authors have contributed equally to this work \\ Correspondence to: Chen Diling, email: diling1983@163.com \\ Xie Yizhen, email: xieyizhen@126.com
}

Keywords: anti-inflammatory, gut microbiota, Hericium erinaceus, immune-enhancing effect, inflammatory bowel disease Received: May 14, $2017 \quad$ Accepted: July 26, $2017 \quad$ Published: September 06, 2017

Copyright: Diling et al. This is an open-access article distributed under the terms of the Creative Commons Attribution License 3.0 (CC BY 3.0), which permits unrestricted use, distribution, and reproduction in any medium, provided the original author and source are credited.

\section{ABSTRACT}

Hericium erinaceus (HE), a traditional edible mushroom, is known as a medicine food homology to ameliorate gastrointestinal diseases. To investigate whether HE is clinically effective in alleviating inflammatory bowel disease (IBD), HE extracts (polysaccharide, alcoholic extracts and whole extracts were prepared using solvent extraction methods) were administrated for 2 weeks in rats with IBD induced by trinitro-benzene-sulfonic acid (TNBS) enema $(150 \mathrm{mg} / \mathrm{kg})$. Significant clinical and histological changes in IBD rats were identified, including damage activity, common morphous and tissue damage index scores in colonic mucosa and myeloperoxidase (MPO) activity. The damage activity, common morphous and tissue damage index scores in colonic mucosa $(P<0.05)$ were improved, MPO activities were decreased. Inflammatory factors were also differentially expressed in colonic mucosa in IBD rats, including serum cytokines, Foxp3 and interleukin (IL)-10 were increased while NF-KB p65 and tumor necrosis factor (TNF)-a were decreased $(P<0.05)$, and T cells were activated $(P<0.05)$, especially in the alcohol extracts-treated group. We also found that the structure of gut microbiota of the $H$. erinaceus extracts-treated groups changed significantly by compared with the model group. Further studies revealed that the polysaccharides in HE extracts may play a prebiotic role, whereas the alcoholic extracts show bactericidin-like and immunomodulatory effects. Taken together, we demonstrated that $\boldsymbol{H}$. erinaceus extracts could promote the growth of beneficial gut bacteria and improve the host immunity in vivo IBD model, which shows clinical potential in relieving IBD by regulating gut microbiota and immune system.

\section{INTRODUCTION}

Inflammatory bowel diseases (IBDs), including ulcerative colitis (UC) and Crohn's disease, are characterized by recurring symptoms of abdominal pain, diarrhea, pus, and bleeding [1]. The incidence and prevalence rates of IBDs have been reported to be increasing worldwide [2]. The etiology and pathogenesis 
of IBD are still unclear; hereditary susceptibility, immune dysfunction, infection, and psychological and environmental factors are predicted to have a certain relationship [3]. Unfortunately, treatments for IBDs are very limited, including mainly 5-aminosalicylic acid preparations [4], corticosteroids, immunosuppressive agents, and some biological agents [5-7]; however, these drugs have different limitations and also have side effects more or less for the patients. Therefore, new drugs and strategies are needed to enhance the clinical responses and outcomes.

Recently, gut microbiota is considered an important factor in the progress of IBD [8-10], although the etiology and pathogenesis of IBD are still unclear and varied. In genetically susceptible individuals, the gut mucosal integrity is damaged and the microbial antigens escape through the epithelial barrier more easily, thereby activating inappropriate immune response or underlying chronic inflammation [11]. The gut microbiota plays an important role in maintaining the intestinal balance by activating the natural Toll-like receptors in the damage and repair process of intestinal mucosal integrity in patients with IBDs $[12,13]$. Previous studies indicated that enteric flora disturbance could cause IBDs in mice and reduce the microbial diversity in patients, as when the intestinal bacteria increased, but some of the Bacteroidetes and Firmicutes decreased [8, 14]. How the enteric flora disturbance influences the IBDs is still unclear. It might be related to invasion of some pathogens and reduction in some protective bacteria, resulting in the activation of some abnormal immune cells, destruction of Th1and Th17-mediated immune responses, increase in the mucous membrane permeability, loss of immune tolerance function, and so on $[8,14]$. Previous studies showed that probiotic bacteria might be useful in preventing and treating acute and chronic conditions including antibioticassociated diarrhea and IBDs [15]. Variation in host physiology caused by different diet, age, lifestyle, genetics and other factors might have a significant impact on microbiota [16-19]. At present, the outcomes of clinical and animal studies on gut microbiota lack consistency, and to understand the impacted gut microbiota function factors need an improved study design and better control over microbiota-mediated effects.

The edible and medicinal fungi are well known and widely used as part of traditional diet and herbs in Asia. In the last decades, the medicinal properties of these fungi have become the core of intense researches in naturally produced pharmaceuticals $[20,21]$. Hericium erinaceus, belonging to the division Basidiomycota and class Agaricomycetes, is both an edible and medicinal mushroom. It is a popular delicacy across the continents and replaces pork or lamb in Chinese vegetarian cuisine. It is rich in active constituents of diterpenoid compounds, steroids, polysaccharides, and other functional ingredients [22]. It is reported that $H$. erinaceus extracts have antimicrobial activities against both antibiotic-resistant and nonresistant (susceptible) pathogenic bacteria [21, 23-26], especially Helicobacter pylori [27, 28], a human gastrointestinal pathogen causing adverse effects including ulcers.

IBD models are diverse [29, 30], and can be broadly categorized into four kinds: chemically induced, biologically induced, genetic (including congenic and genetically modified animals), and cell transfer models. A chemical, 2, 4, 6-trinitrobenzene sulfonic acid (TNBS), is administered rectally in the form of an enema to mice or rats [31]. It is administered in combination with ethanol, which disrupts the mucous barrier. It is generally thought that TNBS induces colitis by haptening -proteins within the gut, making them preferential targets for immune cells. In this study, a rat and mice colitis model was induced with a TNBS enema, and $H$. erinaceus extracts (polysaccharide, alcoholic extracts, and whole extracts) were administered intragastrically for 2 weeks to evaluate the treatment effect, with the aim to seek novel and effective drugs or foods from natural resources to relieve the symptoms.

\section{RESULTS}

\section{Clinical improvements by $\boldsymbol{H}$. erinaceus extracts administration}

After treatment with TNBS enema, the rats in all the groups except for the control were anepithymia with reduced activity, lethargy, weight loss, and ruffled fur, along with bloody stools or occult blood. However, these symptoms disappeared from day 9 or day 10 . The results of DAI after 14 days of treatments are shown in Figure 1A. The rats in the $H$. erinaceus extracts-treated groups showed significant improvement compared with the TNBS-treated group.

\section{Histological improvements by $H$. erinaceus extracts administration}

After 14 days of treatment, the rats were killed and their colons were dissected. Hematoxylin and eosin (H\&E)-stained sections showed mucosal erosions and ulceration in the TNBS-induced group (Figure 1, model group) compared with the normal group (Figure 1, normal group). The lesions were situated in the mucosa and submucosa, with architectural disruption of the colonic crypts and an inflammatory infiltrate in the mucosa including neutrophils, lymphocytes, and macrophages. Variable crypt architecture was observed, from distorted and dilated to decrease and absent. In addition, occasional crypt abscesses were considered. Injuries of the $H$. erinaceus extracts-treated groups were significantly less severe compared with the TNBS-induced group. 

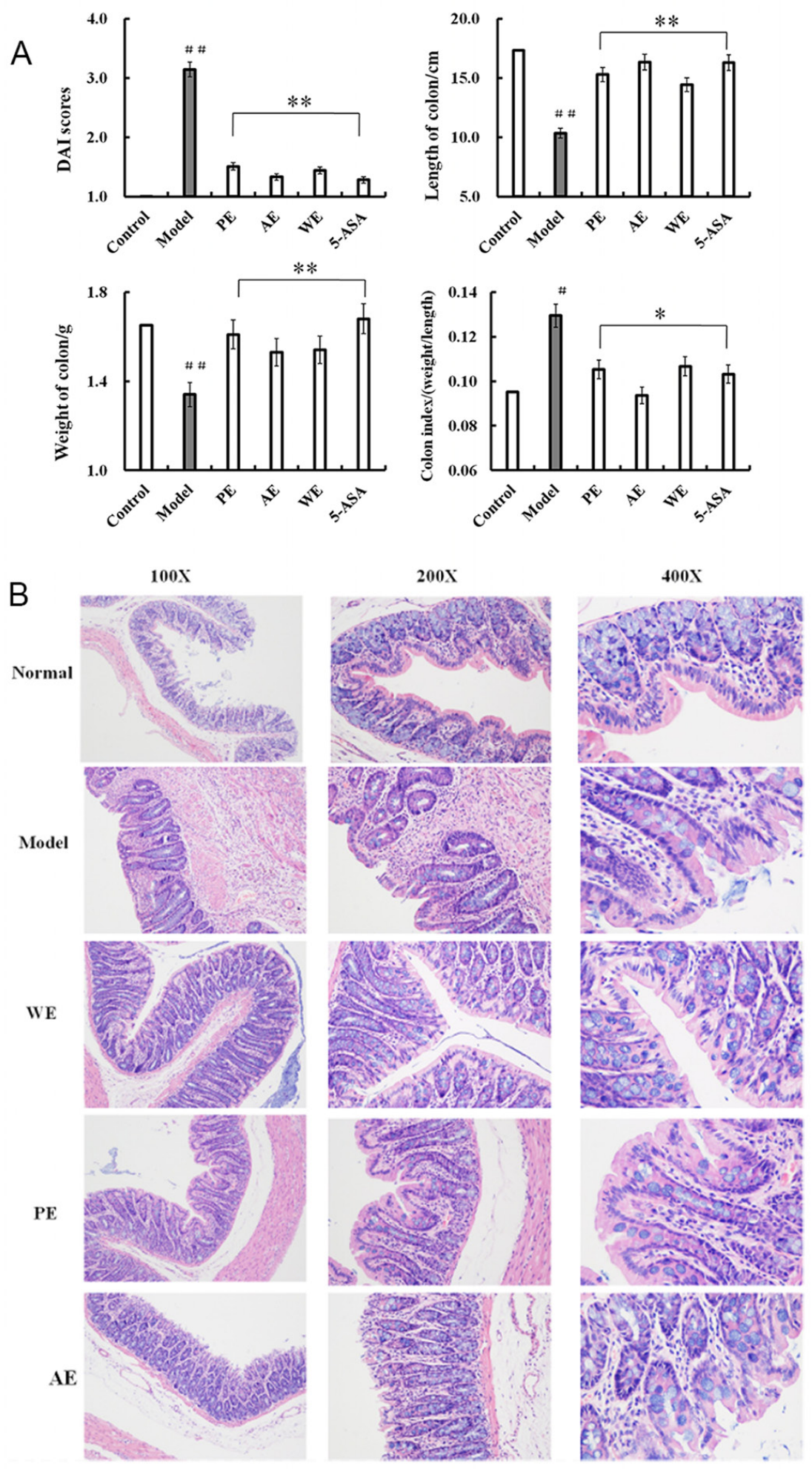

Figure 1: DAI scores and histopathological changes in the colon of rats in differently treated groups after induction by TNBS. DAI scores were calculated according to the (A) weight loss, stool consistency, and blood in feces, length of the colon, weight of the colon, and the colon index (weight/length), with six rats per group; (B) histopathological changes in the colon. Normal, group without any treatment; model, the TNBS-induced group; WE, the whole extract-treated group after TNBS induction; PE, the polysaccharides extract-treated group after TNBS induction; AE, the alcohol extracts-treated group after TNBS induction. Values are expressed as means \pm standard deviation. ${ }^{\#} P<0.05$ vs the control group, ${ }^{*} P<0.05,{ }^{*} P<0.01$ vs the model group, indicating significant differences compared with the model group. 


\section{Amelioration of the expression levels of serum cytokines}

After 14 days of treatment, the serum levels of IL$1 \alpha$, IL-2, IL-8, IL-10, IL-11, IL-12, TNF- $\gamma$, TNF- $\alpha$, VGEF, MIP- $\alpha$, and M-CSF were monitored. As shown in Figure 2 , the proinflammatory cytokine levels of IL-1 $\alpha$ (Figure
2A), IL-8 (Figure 2C), IL-12 (Figure 2F), TNF- $\alpha$ (Figure $2 \mathrm{G}$ ), VGEF (Figure 2I), and MIP- $\alpha$ (Figure $2 \mathrm{~K}$ ) increased $(P<0.05)$ after the rats were injected with $150 \mathrm{mg} / \mathrm{kg}$ of TNBS enema, while the anti-inflammatory cytokines levels of IL-2 (Figure 2B), IL-10 (Figure 2D), IL-11 (Figure 2E), TNF- $\gamma$ (Figure 2H), and M-CSF (Figure 2J) decreased, compared with the normal group $(P<0.05)$.
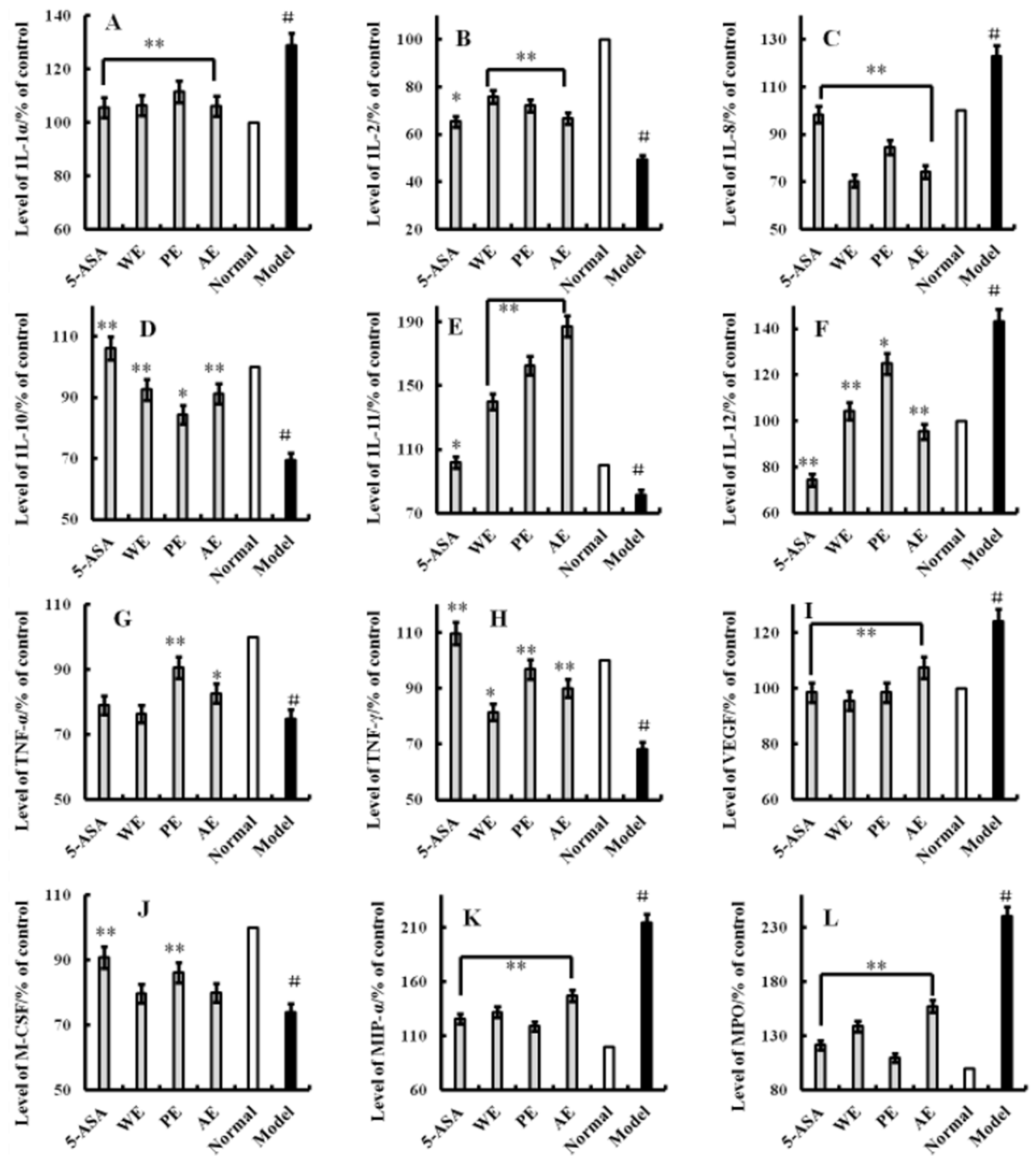

Figure 2: Effects of $\boldsymbol{H}$. erinaceus extracts on TNBS-induced rats. Rats in the normal and model groups were induced by TNBS; WE, the whole extract-treated group after TNBS induction; PE, the polysaccharides extract-treated group after TNBS induction; AE, the alcohol extract-treated group after TNBS induction. The positive control group was treated with $100 \mathrm{mg} /(\mathrm{kg} \cdot$ day) of 5-aminosalicylic acid. After treatment for 14 days, the cytokines IL-1 $\alpha$ (A), IL-2 (B), IL-8 (C), IL-10 (D), IL-11 (E), IL-12 (F), TNF- $\alpha$ (G), TNF- $\gamma$ (H), VGEF (I), M-CSF (J), MIP- $\alpha(\mathbf{K})$ and MPO (L) were produced. The assays were carried out according to the procedures recommended in the enzymelinked immunosorbent assay kit manual. Values were means \pm standard deviation of three independent experiments. ${ }^{\#} P<0.05$ vs the normal group, ${ }^{*} P<0.05,{ }^{* *} P<0.01$ vs the TNBS-treated group, indicating significant differences compared with the LPS-treated group. 
This indicated that the inflammation was induced with the TNBS enema. After treatment with $H$. erinaceus extracts, all the cytokines levels were restored to near normal; some anti-inflammatory cytokines were secreted significantly and were better than the positive control group $(P<0.05)$. All the results demonstrated that the $H$. erinaceus extracts could be potential drugs and food resources for treating IBDs.

\section{Decrease in the expression of tissue myeloperoxidase}

Neutrophils were the main inflammatory cells in the damaged colonic tissue, leading to an increased level of myeloperoxidase (MPO). The MPO level was decreased according with the degree of inflammation, as shown in Figure 2L. The MPO level in the TNBS-induced rats was significantly higher than that in the normal group $(P<0.05)$. The MPO level in tissues from $H$. erinaceus extracts-treated groups was significantly lower compared with the TNBS-induced group $(P<0.05)$. The result indicated that extracts from $H$. erinaceus reduced the degree of inflammation of the colon in IBD rats.

\section{Amelioration of the expression of colonic Foxp3, NF- $\kappa$ B p65, TNF- $\alpha$, and IL-10 proteins}

All sections were observed under the same conditions using a light microscope (Figure 3). The brown particles in the nucleus or in the cytoplasm were considered as positive cells. The proportion of Foxp3and IL-10-positive cells in rats in the model group was significantly lower than that in the normal group $(P<$ $0.05)$, while the levels of TNF- $\alpha$ and NF- $\kappa \mathrm{B}$ p65 were significantly higher $(P<0.05)$. After treatment with $H$. erinaceus extracts, the proportion of Foxp3- and IL-10positive cells significantly increased, especially in the alcoholic extracts $(\mathrm{AE})(P<0.05)$, compared with the model group. Nevertheless, the proportion of TNF- $\alpha-$ and NF- $\mathrm{B}$ p 65 - positive cells was significantly reduced compared with the model group $(P<0.05)$. Cumulatively, these results suggested that $H$. erinaceus extracts had effective anti-inflammatory effects in IBD.

\section{The gut microbiota structure significantly changed by $\boldsymbol{H}$. erinaceus extracts administration}

Operational taxonomic unit (OTU) abundance and taxonomic profiles were analyzed as shown in Figure 4. We also constructed and visualized a taxonomic tree of the predominant taxa (Figure 6). All the treated groups can be clustered well using Bray-Curtis distance. The gut microbiota structure of the AE-treated group was close to the normal rats, while the PE-treated group were close to the model rats, and the WE-treated group was neither different from the normal nor the TNBS-induced group
(Figure 4), which indicated that the alcoholic extracts (AE) of $H$. erinaceus may regulate the gut microbiota to the normal-like structure in the TNBS-induced IBD rats as the main active ingredients of $H$. erinaceus.

\section{Analysis of mechanical contribution to bacterial dynamic balance}

Metastats analysis revealed the difference of taxonomic abundance between different groups together with FDR correction, as revealed in Figure 5. Some bacteria in the fecal samples sharply changed from the family classification level. Moreover, at the genus level, the TNBS-induced rats exhibited enrichment of potentially proinflammatory microbes, such as Corynebacterium, Staphylococcus, Ruminococcus, Roseburia, Dorea, and Sutterella, and reduction of potentially anti-inflammatory microbes, such as Bacteroides, Bifidobacterium, Prevotella, Parabacteroides, Coprococcus, Desulfovibrio, and Lactobacillus [32-34], compared with the normal group (Figure 6). However, treatment with the $H$. erinaceus extracts exhibited reduction in proinflammatory microbes and enrichment of anti-inflammatory microbes, especially in the AE-treated group. All the results indicated that the $H$. erinaceus extracts had the potential to regulate the gut microbiota structure.

\section{Prebiotic effect of polysaccharides in H. erinaceus extracts on TNBS-induced mice}

An IBD mice model was prepared after treatment with broad-spectrum antibiotic for 1 week to extensively evaluate the prevention and cure effects of polysaccharides on IBD. As shown in Figure 7, the colonic tissues were seriously damaged in the TNBS-combined antibioticstreated groups, and some cytokines such as GM-CSF, TNF- $\gamma$, IL-10, IL-12, IL-17 $\alpha$, IL-4, TNF- $\alpha$, VGEF- $\alpha$, and LPS were far from the control, indicating that without the microbiota the intestinal mucosa (Figure 7D) could be easily destroyed (Figure 7C). When treated with $H$. erinaceus polysaccharides, especially the combined Bifidobacterium-treated groups, all the cytokine levels were restored to near normal, and even some clinical parameters were significantly better than those in the control group $(P<0.05)$. Moreover, the immunohistochemical staining showed that the expression of NF- $\kappa \mathrm{B}, \mathrm{TNF}-\alpha$, and IL-17 in the polysaccharide- and Bifidobacterium-treated groups decreased compared with the model $(P<0.05)$ and TNBS-combined antibioticstreated groups $(P<0.01)$; however, the expression of Foxp3 increased $(P<0.01)$, as shown in Figure 8 .

Further statistical analysis revealed that the polysaccharides could significantly enhance the settling down of Bifidobacterium $(P<0.05$; Figure 9). Moreover, the other prebiotics increased. The results showed that the $H$. erinaceus polysaccharides could be useful as prebiotics. 


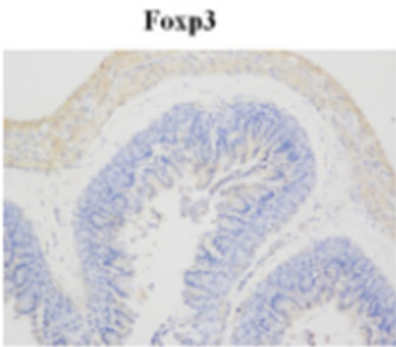

Control

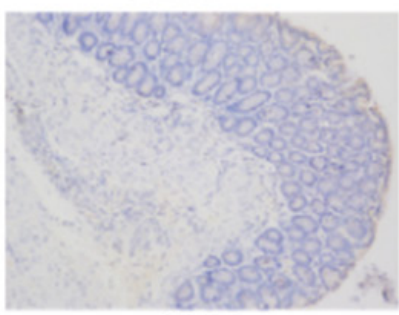

Model

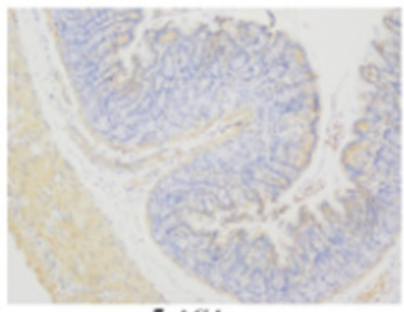

5-ASA

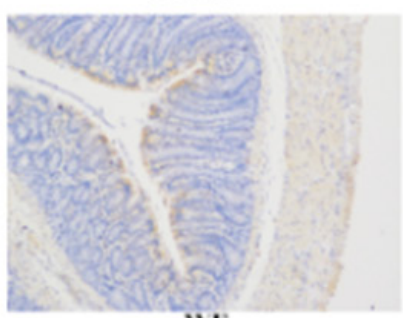

WE

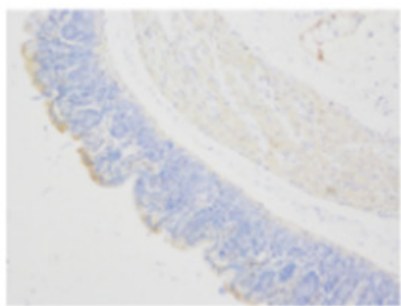

PE.

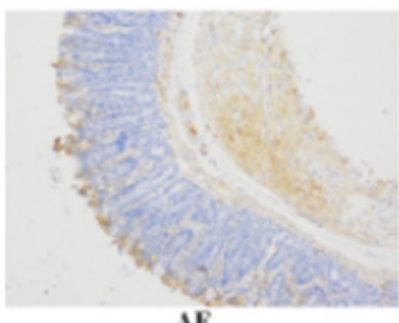

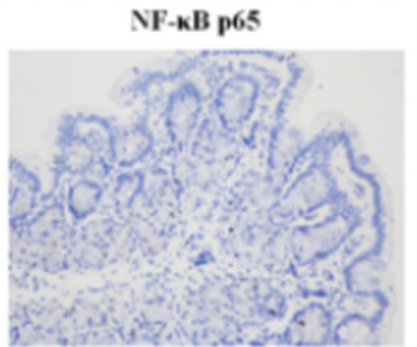

Control

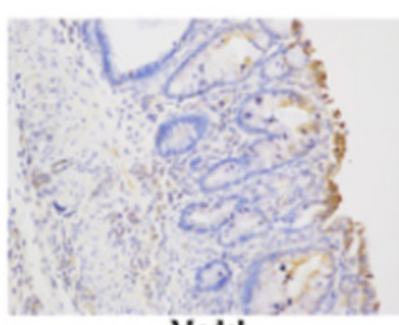

Model

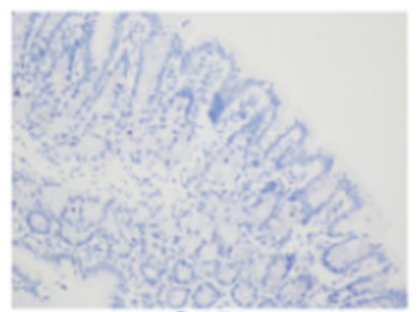

5-ASA

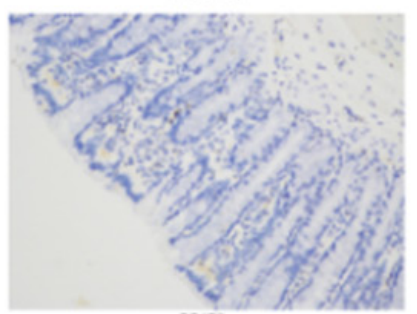

WE

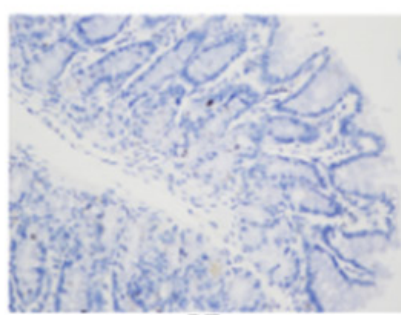

PE

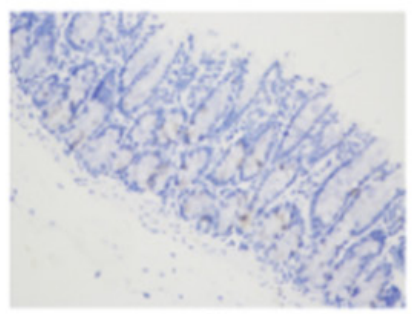

AF
TNF- $\boldsymbol{a}$

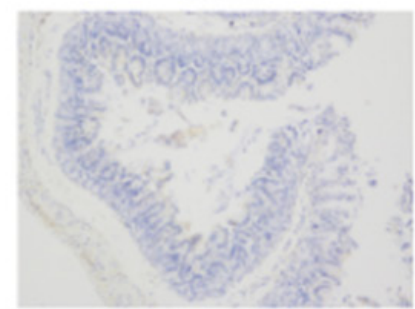

Control

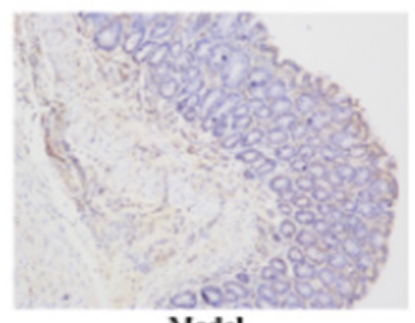

ModeI

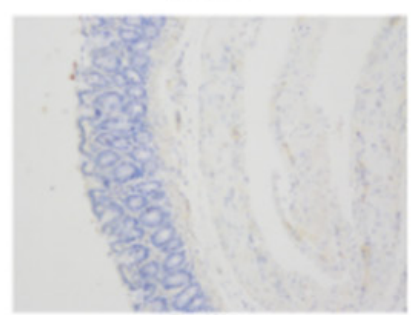

5-ASA

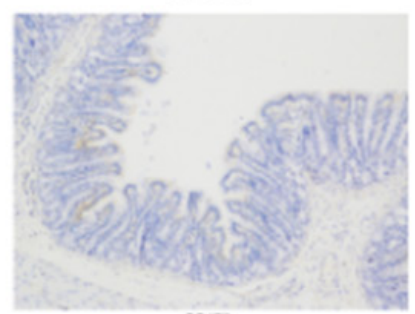

WE

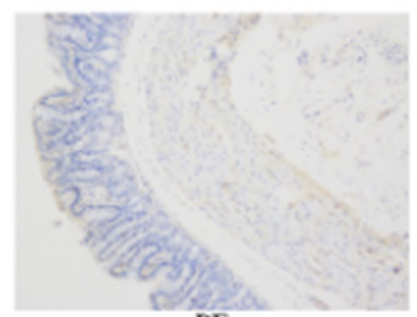

PE

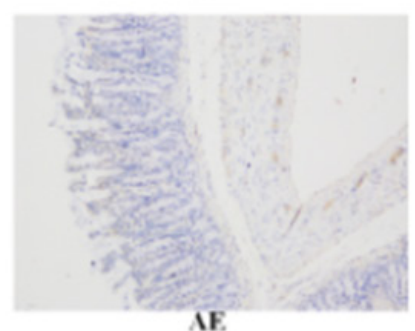

IL-10

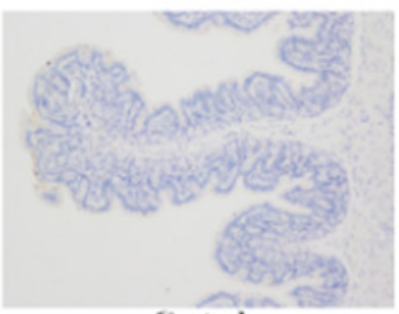

Control

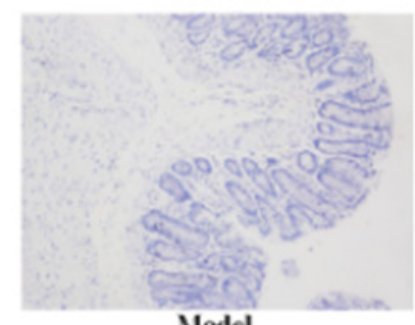

Model

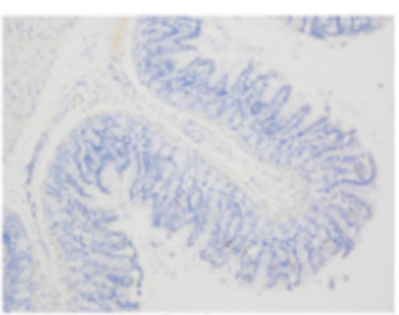

5-A A

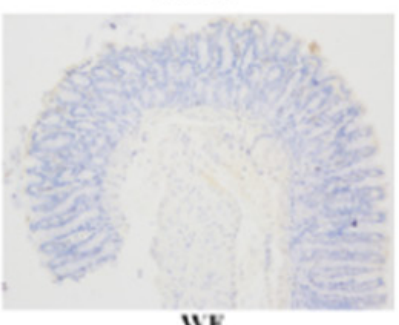

WE

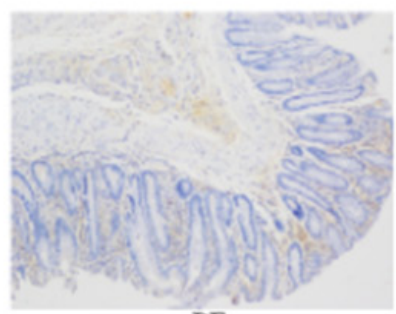

PE.

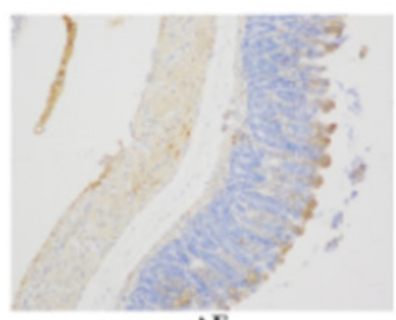

AE.

Figure 3: Immunohistochemistry staining of Foxp3, NF-кB p65, TNF- $\alpha$, and IL-10 in the colons of different experimental groups $(\times \mathbf{2 0 0})$ in IBD rats. Rats in the normal without nothing treatment, and model groups were induced by TNBS; WE, the whole extract-treated group after TNBS induction; PE, the polysaccharides extract-treated group after TNBS induction; AE, the alcohol extract-treated group after TNBS induction. 


\section{DISCUSSION}

Mushrooms are generally a good source of nutrients and health-promoting compounds. The findings of the present study showed that the $H$. erinaceus extracts (polysaccharide, alcoholic extracts, and whole extracts) significantly improved the structure of gut microbiota. Some symptoms of IBD such as common morphous and tissue damage index scores in colonic mucosa improved
$(P<0.05)$; the MPO activity decreased; the levels of serum cytokines, including IL-1 $\alpha$, IL-2, IL-8, IL-10, IL11 , IL-12, TNF- $\gamma$, TNF- $\alpha$, VGEF, MIP- $\alpha$, and M-CSF levels, improved to near normal; and the expression of Foxp3, NF- $\mathrm{kB}$ p65, TNF- $\alpha$, and IL-10 in colonic mucosa improved $(P<0.05)$. These results clearly indicated that the $H$. erinaceus extracts could promote the growth of probiotic bacteria, improve immunity, and give positive results in the experimental models of IBD.

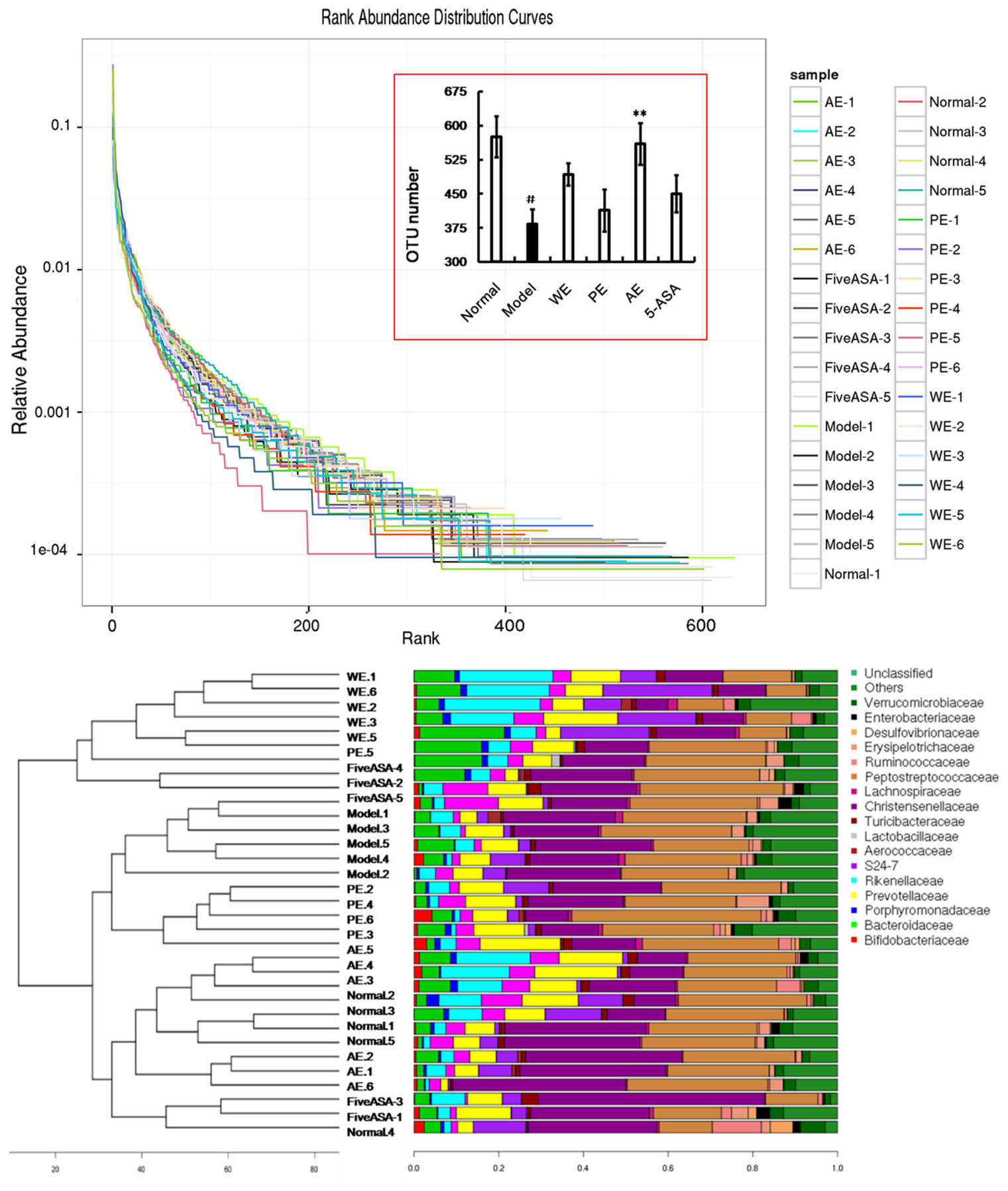

Figure 4: The Bray coefficient of cluster analysis and stacked figure of family composition based on the best classification level of the IBD rats induced by TNBS enema. 
Immune factors play a predominant role in the pathogenesis of IBDs. Cytokines, including IL-1, IL-2, IL-12, TNF- $\alpha$, VGEF, and MIP- $\alpha$, were proinflammatory, while IL-8, IL-10, IL-11, TNF- $\gamma$, and M-CSF were antiinflammatory. These cytokines have various biological activities such as transferring molecules, mainly regulating the immune response, participating in the immune cell differentiation development and tissue repair, interfacing inflammation, and stimulating hematopoietic function and other functions. Anti-inflammatory and immunosuppressive treatments are well known for reducing and limiting the damage caused by IBD. Studies have shown that the inflammatory mediators and the pathological changes in colonic mucosa are mainly affected in IBD. The interleukins, such as IL-1, IL4, IL-6, IL-8, and IL-10, were considered to be closely associated with UC. TNF- $\alpha$ helps in the infiltration of the inflammatory cells into the bowel, increasing the intestinal mucosal inflammation; promoting the release of plateletactivating factor, leukotriene, and oxygen free radical; and inducing nitric oxide synthesis leading to cell damage [35]. TNF- $\alpha$, with its accomplice IL-6, induces the thrombin or even microthrombus formation on intestinal mucosa [36], leading to microcirculation disorder, grievous ischemia, and anoxia. The underlying mechanism is that free radicals and TNF- $\alpha$ lead to the degradation of $\mathrm{I}-\kappa \mathrm{B}$, an inhibitory protein of NF- $\kappa \mathrm{B}$, in turn resulting in NF- $\kappa \mathrm{B}$ activation and induction of downstream target genes, as shown in Figure $10 \mathrm{~A}$. The expression of NF- $\kappa \mathrm{B}$ increased after confluent cultures with $1 \mu \mathrm{g} / \mathrm{mL}$ TNF- $\alpha$ and $1 \mu \mathrm{g} / \mathrm{mL}$ LPS. When treated with AE, the expression levels decreased slightly, indicating that $\mathrm{AE}$ could down regulate the expression of $\mathrm{NF}-\kappa \mathrm{B}$ to suppress inflammation directly. In this study, the TNF- $\alpha$ levels were higher in the peripheral blood and colons of the TNBS-induced rats than in the normal group; also the expression of $\mathrm{NF}-\kappa \mathrm{B}$ in the colons was activated, and the levels of IL- $1 \alpha$, IL-2, IL-8, IL-10 were changed. However, after treatment with the $H$. erinaceus extracts, all the inflammatory responses were ameliorated.

Foxp3 is a member of the forkhead family of transcription factors critically involved in the development and function of $\mathrm{CD}^{25+}$ regulatory $\mathrm{T}$ cells (Treg). It regulates not only the expression of $\mathrm{CD}^{4+} \mathrm{CD}^{25+}$ Treg (as a specific marker) but also the expression of $\mathrm{CD} 8^{+} \mathrm{CD} 28^{-}$ Treg. It was found that the number of $\mathrm{CD}^{4+} \mathrm{CD}^{25+}$ Treg cells decreased in the Foxp3 gene knockout or mutation mice,

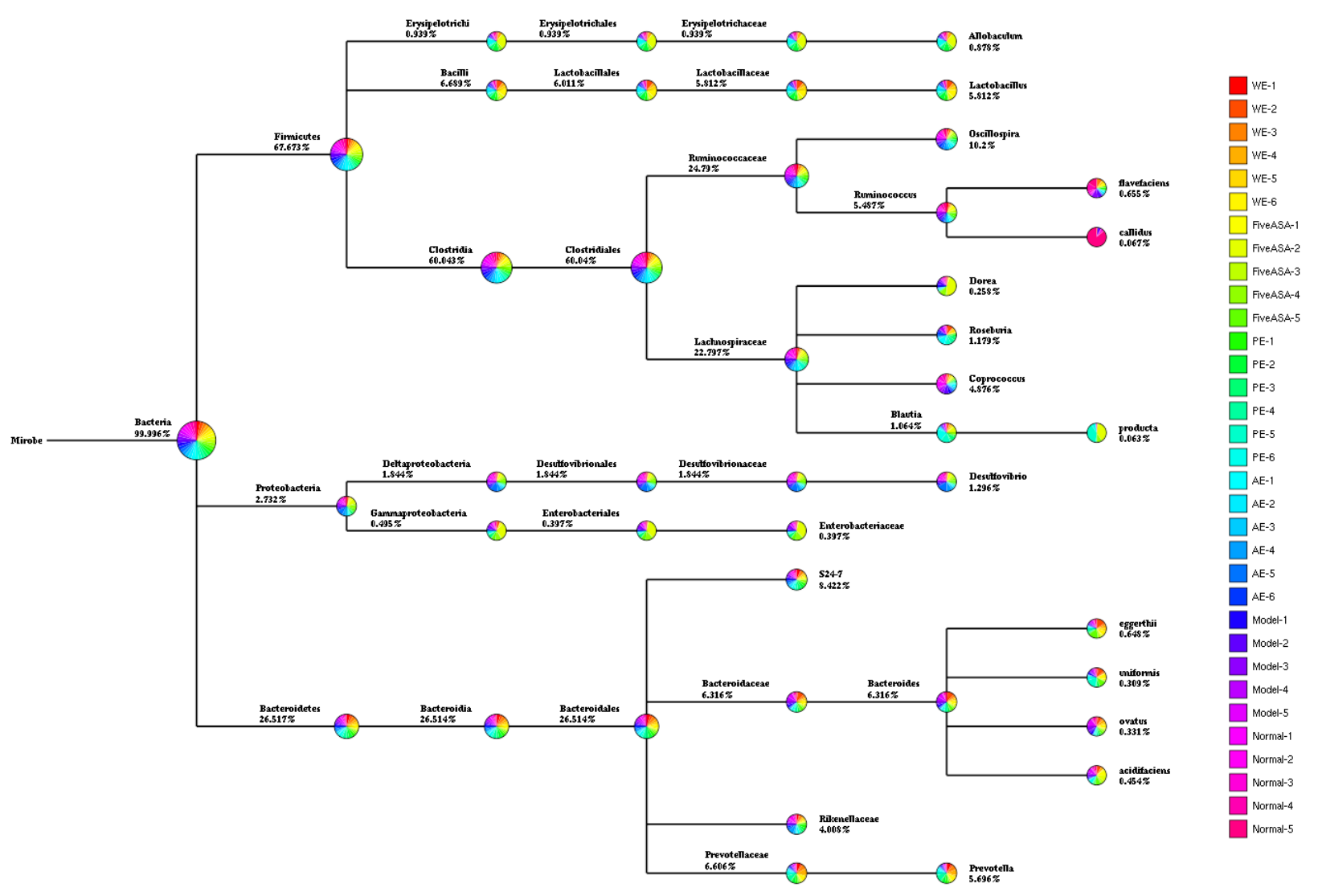

Figure 5: Tree species classification of the differently treated samples from IBD rats induced by TNBS enema. The pie chart of different colors represents different samples in that classification unit. The size of the radius denotes the tag number accounts for the proportion of the total tag; the larger the radius, the higher the abundance. The numbers next to the pie chart represent the percentage of tag number of the percentage of the total tag. 

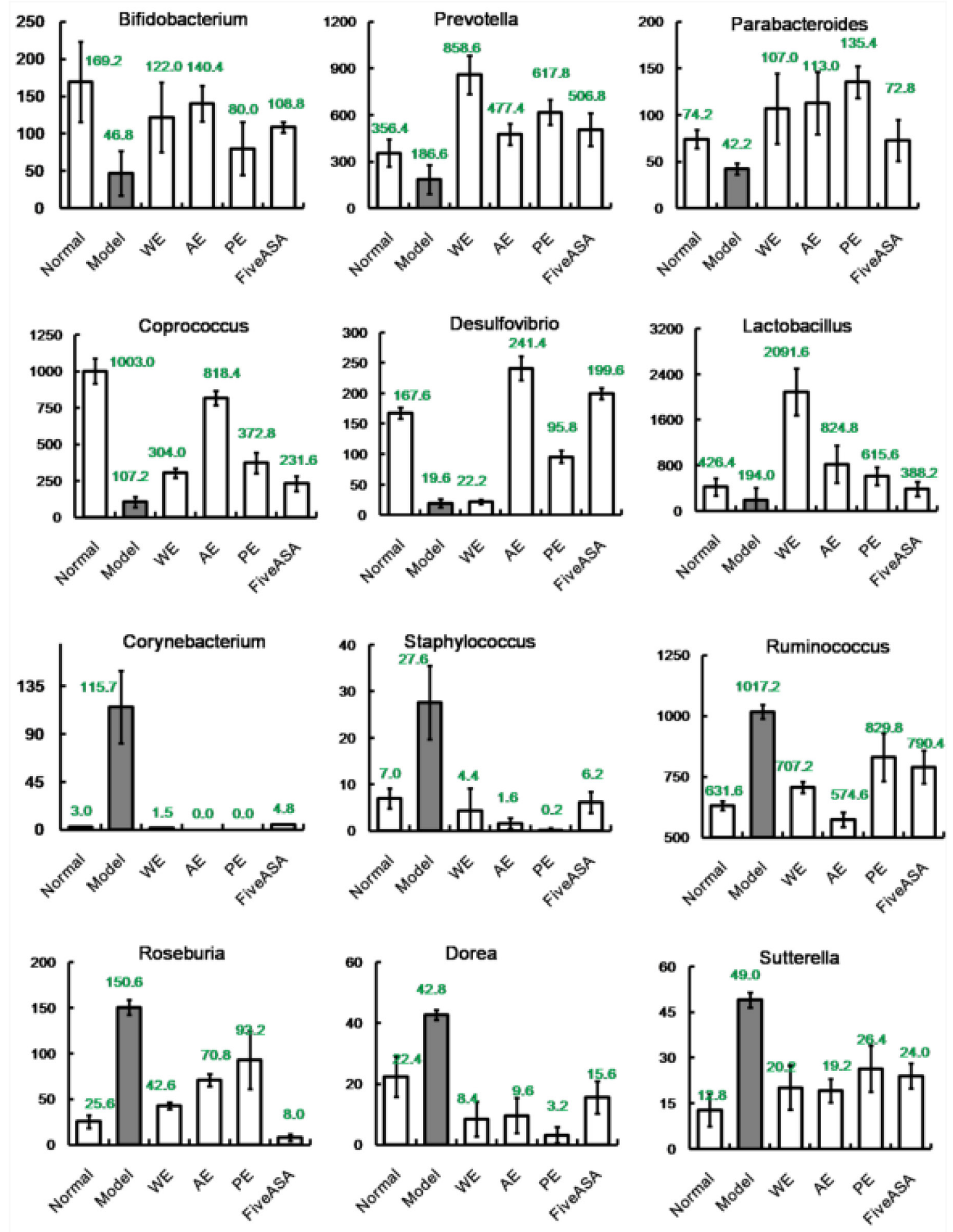

Figure 6: Tags with significant differences in the relative abundance of different grouping distribution of genus in IBD rats induced by TNBS enema. 

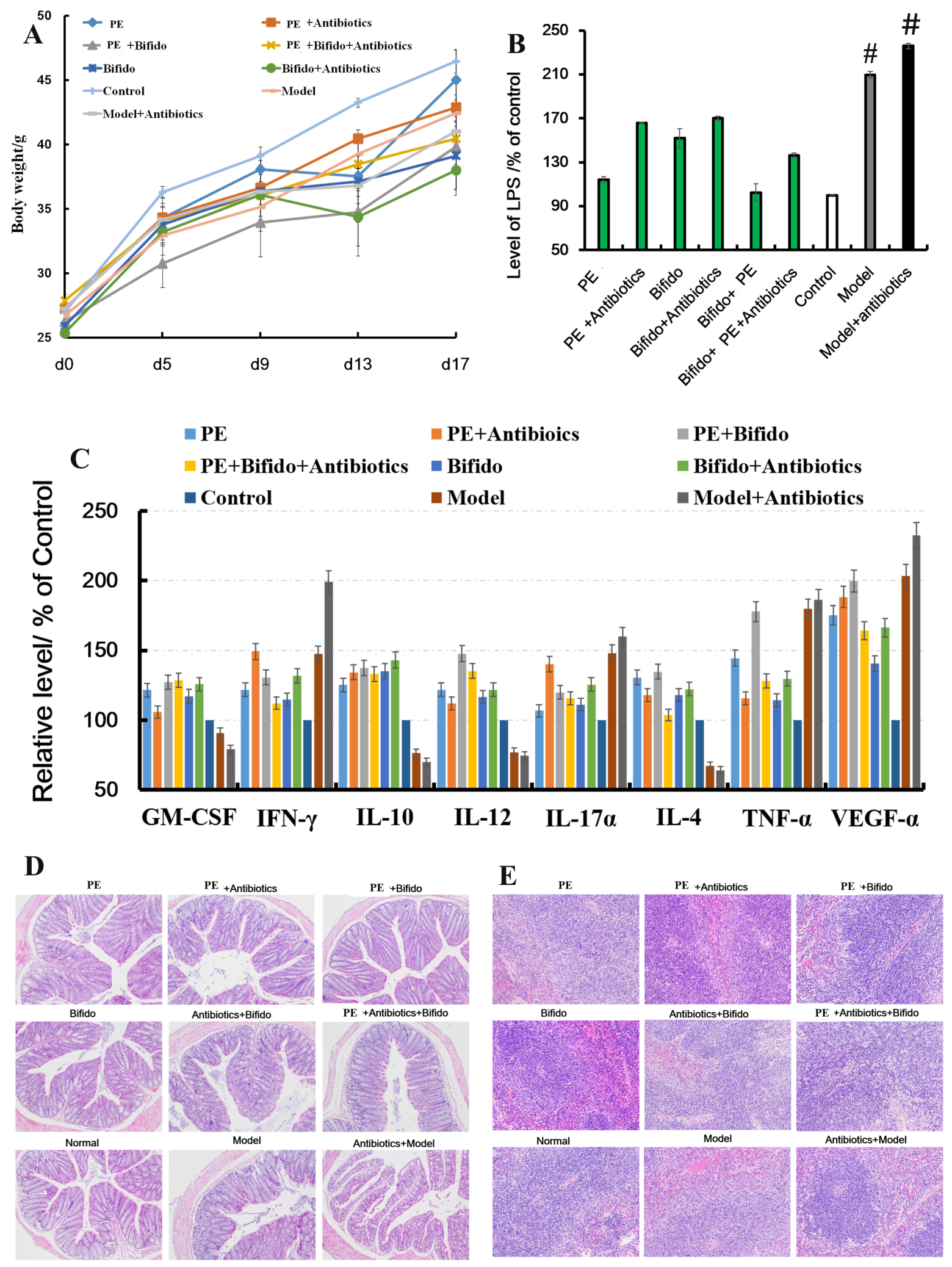

Figure 7: Polysaccharides extracted from $\mathrm{H}$. erinaceus improved the pathological parameters of the TNBS-induced mice. (A) Body weight changes; (B) levels of LPS in serum; (C) levels of cytokines GM-CSF, TNF- $\gamma$, IL-10, IL-12, IL-17 $\alpha$, IL-4, TNF- $\alpha$, and VGEF- $\alpha$ in serum; (D) histopathological changes in the colon; and (E) histopathological changes in the spleen. Control is the normal without any treatments; model (Mice were induced by TNB), model and high-dose antibiotics, polysaccharides $[100 \mathrm{mg} /(\mathrm{kg}$ - d)], Bifidobacterium, polysaccharides plus high-dose antibiotics, polysaccharides plus Bifidobacterium, Bifidobacterium plus high-dose antibiotics, and polysaccharides plus Bifidobacterium plus high-dose antibiotics. 

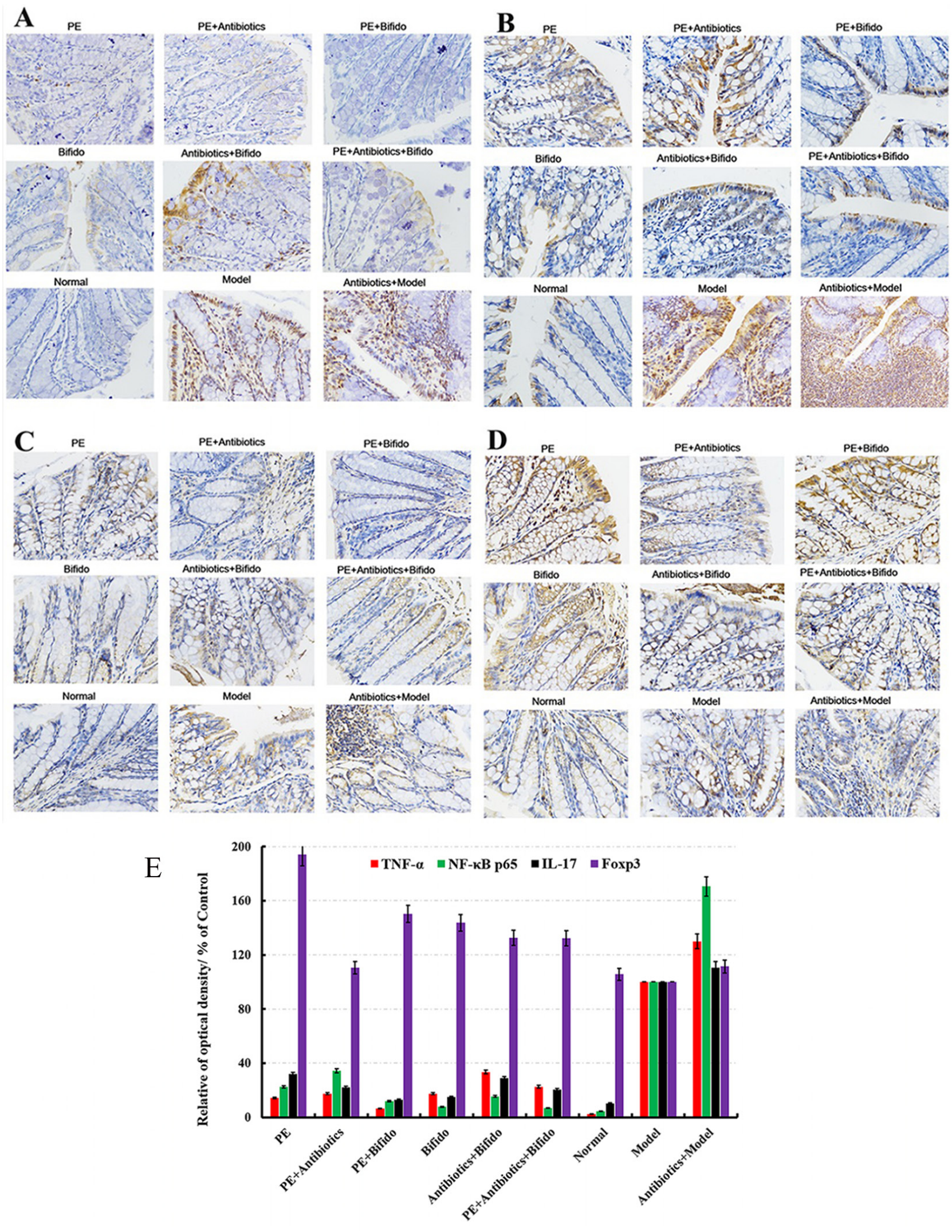

Figure 8: Immunohistochemistry staining of (A) TNF- $\alpha$, (B) NF-kB p65, (C) IL-17, (D) Foxp3 and the mean optical density values were used for analyzing the results of immunohistochemistry (E) in the colons of different experimental groups in IBD mice induced by TNBS enema after treatment with polysaccharides extracted from $\mathrm{H}$. erinaceus. 
greatly increasing the incidence of autoimmune diseases [37]. The homologous Foxp3 mutations were proved to cause genetic disorders in humans, such as immune disorders, bowel diseases, and endocrine diseases [38]. The expression of Foxp3 was markedly inhibited in the TNBS-treated rats in the present study (Figure 3 ). The number of $\mathrm{CD}^{4+} \mathrm{CD}^{25+}$ Treg cells increased in the peripheral blood of rats after treatment with the $H$. erinaceus extracts compared with the TNBS-treated group (Figure 10B, $P$ $<0.05$ ), indicating that the $H$. erinaceus extracts could activate the immune system of IBD.

A new study reported that Bacteroides friagilis delivered immunomodulatory molecules to immune cells via secretion of outer membrane vesicles to Treg to suppress the mucosal inflammation in IBD [39], as shown in Figure 10C. The relative abundance of $B$. friagilis was higher in the AE-treated group than in the model group $(P<0.05)$. A previous study also indicated that shortchain fatty acids led to increased Treg cell differentiation via the small intestine, and middle- and long-chain fatty acids supported Th1 and Th17 cell differentiation [40]. Abundant fatty acids were found in AE using the gas chromatography-mass spectrometry (GC-MS) analysis (Figure 10D). Thus, this study confirmed that the fatty acids in AE were one of the pharmacodynamic ingredients of IBD. Previous studies also reported that $H$. erinaceus was rich in erinacines (3-hydroxyhericenone F, hericenone $\mathrm{G}$, hericenone $\mathrm{F}$, and hericerin, and so on) that have antimicrobial and wound-healing properties among other therapeutic potentials [24, 26, 41, 42], which was consistent with the results of the present study. However, the details of the pharmacodynamic ingredients still need more study.

Previous studies also reported that $H$. erinaceus was rich in some physiologically important components, especially $\beta$-glucan polysaccharides. The GC-MS analysis in this study revealed that the monosaccharide composition was mannose $(\sim 55.70 \%)$, arabinose $(\sim 0.7 \%)$, rhamnose $(\sim 3.75 \%)$, xylose $(\sim 1.60 \%)$, galactose $(\sim 5.12 \%)$, and glucose $(\sim 33.10 \%)$. The polysaccharides were demonstrated to have a good prebiotic effect in this study, synergistically relieving inflammation and enhancing immunity (Figure 10). The expression levels of TNF- $\alpha$ (Figure 8A), NF- $\mathrm{BB}$ (Figure 8B), and IL-17 (Figure 8C) in polysaccharides plus Bifidobacterium-treated group were lower while the levels of Foxp3 (Figure 8D) significantly increased $(P<0.05)$ compared with the other treated groups, even more perfect than the normal, indicating that polysaccharides could activate the immune system and inhibit the reaction of inflammation; the mechanism was related to the Foxp3 T cells.

The physical health depends much on the intestinal health. Probiotics play many important roles in maintaining the intestinal health, such as making

\section{Genus}
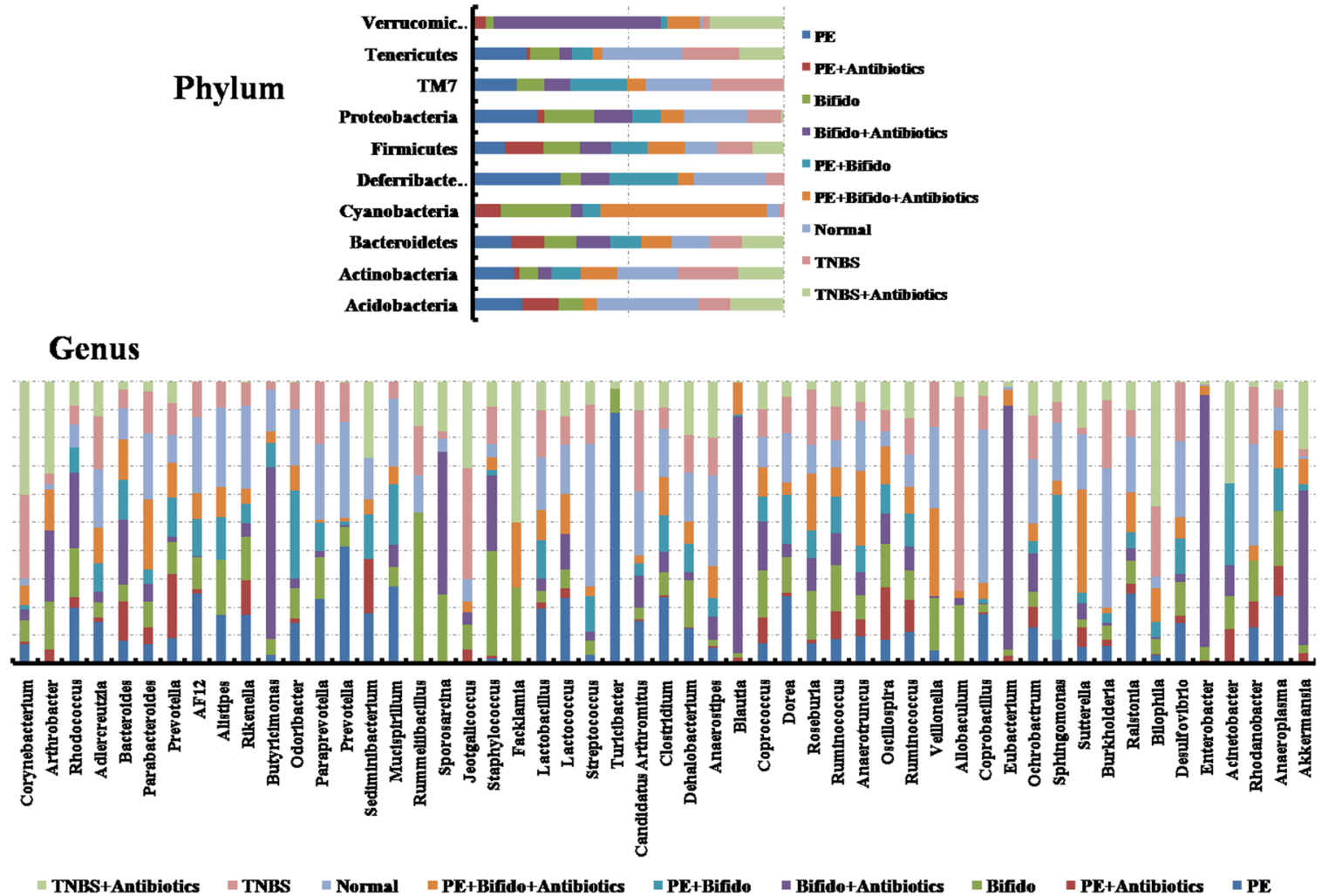

Figure 9: Polysaccharides extracted from H. erinaceus showed a good prebiotic effect on TNBS-induced mice. 

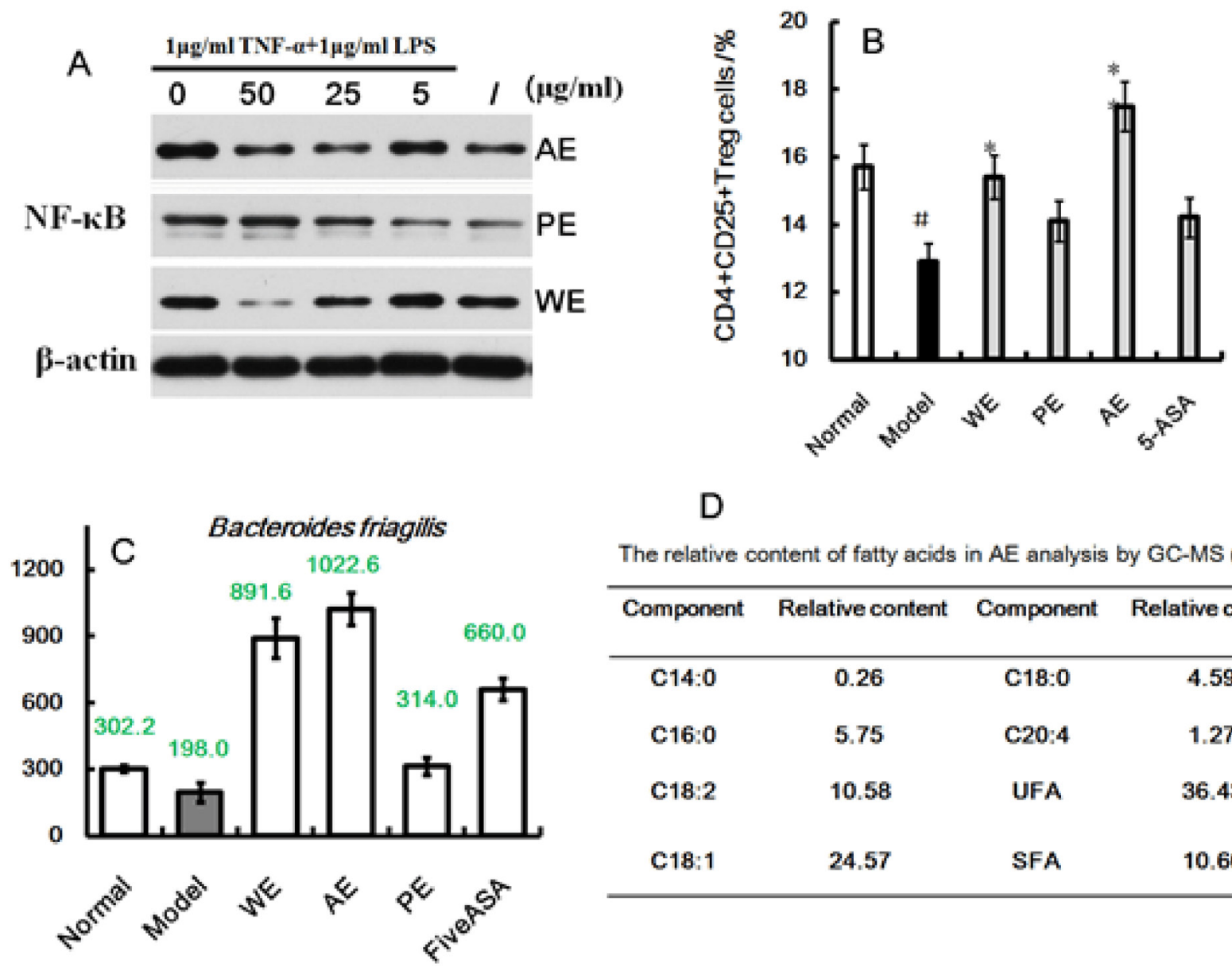

The relative content of fatty acids in AE analysis by GC-MS (mg/g)

\begin{tabular}{cccc}
\hline Component & Relative content & Component & Relative content \\
\hline C14:0 & 0.26 & C18:0 & 4.59 \\
C16:0 & 5.75 & C20:4 & 1.27 \\
C18:2 & 10.58 & UFA & 36.43 \\
C18:1 & 24.57 & SFA & 10.60 \\
\hline
\end{tabular}

Figure 10: Effect of AE on the TNF- $\alpha$ - and LPS-induced Caco- 2 cells (A), $\mathrm{CD}^{4+} \mathrm{CD}^{25+}$ Treg cells in TNBS-induced IBD rats induced by TNBS enema (B), relative abundance of $B$. friagilis differently treated IBD rats (C), and the relative content of fatty acids in AE from $H$. erinaceus analysis by GC-MS (D).

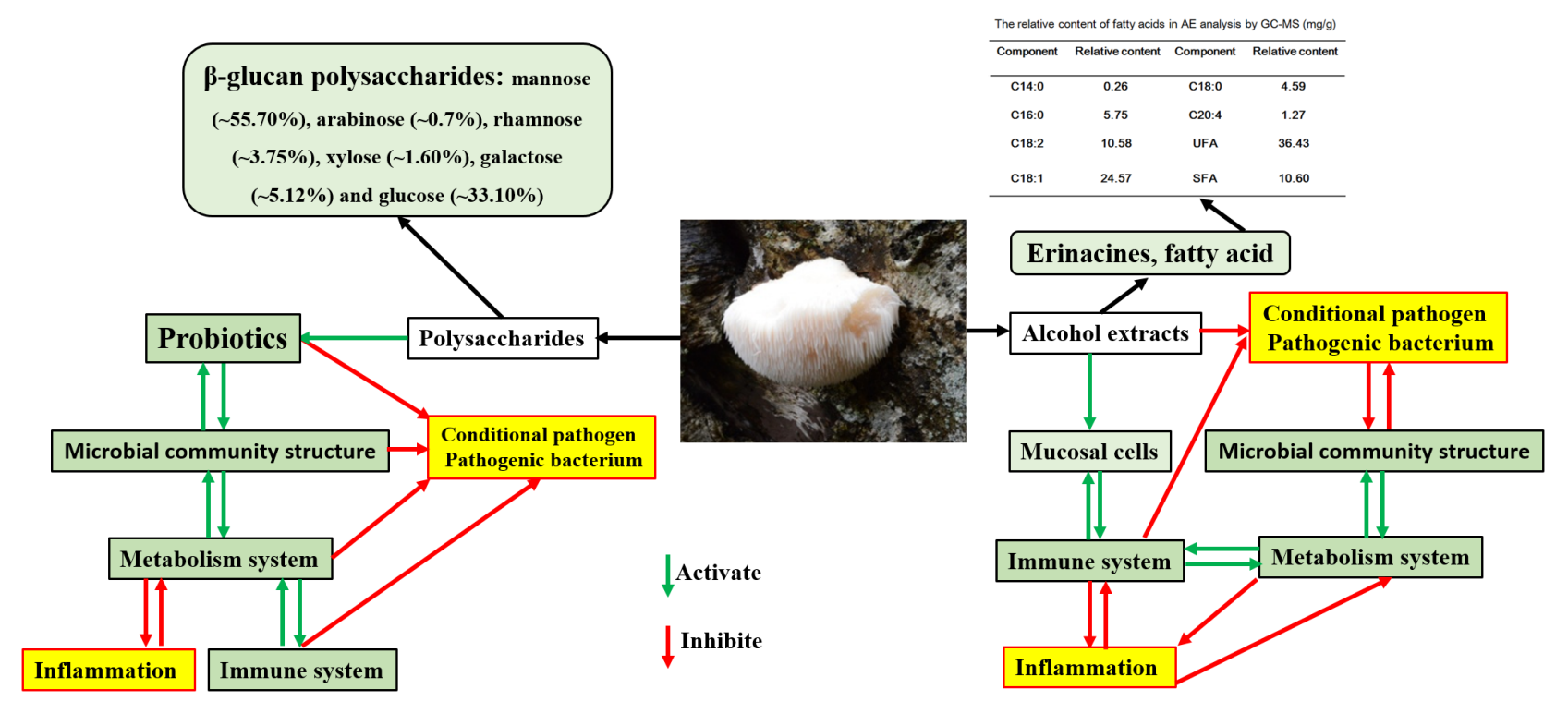

Figure 11: Active ingredients and mode of action of $H$. erinaceus for IBD prevention and treatment. 
Table 1: Experimental design of extracts effects in TNBS-induced IBD rats

\begin{tabular}{lccc}
\hline Groups & Rats No. & $\begin{array}{c}\text { Trinitro-benzene-sulfonic } \\
\text { acid (TNBS) (mg/kg) }\end{array}$ & Dose (mg/kg/d) \\
\hline Normal & 5 & $/$ & Distilled water \\
Model & 5 & 150 & Distilled water \\
Amino saliciylic acid (5- & 5 & 150 & 100 \\
ASA) & 5 & 150 & 100 \\
Whole extracts (WE) & 5 & 150 & 100 \\
Alcoholic extracts (AE) & 5 & 150 & 100 \\
Polysaccharide (PE) & & & \\
\hline
\end{tabular}

Table 2: Experimental design of prebiotic effect of polysaccharides from $\mathrm{H}$. erinaceus extracts in TNBS-induced mice

\begin{tabular}{lccc}
\hline Groups & Mice No. & TNBS (mg/kg) & Dose \\
\hline Control & 9 & $/$ & Distilled water \\
Model & 9 & 150 & Distilled water \\
$\begin{array}{l}\text { Model \& high-dose } \\
\text { antibiotics }\end{array}$ & 9 & 150 & $0.2 \mathrm{ml}$ \\
$\begin{array}{l}\text { Polysaccharides } \\
\text { Bifidobacterium }\end{array}$ & 9 & 150 & $100 \mathrm{mg} / \mathrm{kg} / \mathrm{d}$ \\
$\begin{array}{l}\text { Polysaccharides \& high-dose } \\
\text { antibiotics }\end{array}$ & 9 & 150 & $10^{9} \mathrm{CFU}$ \\
$\begin{array}{l}\text { Polysaccharides \& } \\
\text { Bifidobacterium }\end{array}$ & 9 & 150 & $100 \mathrm{mg} / \mathrm{kg} / \mathrm{d}$ \\
$\begin{array}{l}\text { Bifidobacterium \& high-dose } \\
\text { antibiotics }\end{array}$ & 9 & 150 & $100 \mathrm{mg} / \mathrm{kg} / \mathrm{d}+10^{9} \mathrm{CFU}$ \\
$\begin{array}{l}\text { Polysaccharides \& } \\
\text { Bifidobacterium \& high-dose } \\
\text { antibiotics }\end{array}$ & 9 & 150 & $10^{9} \mathrm{CFU}+0.2 \mathrm{ml}$ \\
\hline
\end{tabular}

Notes: Antibiotics (ampicillin, $2 \mathrm{~g} / \mathrm{L}$; vancomycin, $1.0 \mathrm{~g} / \mathrm{L}$; neomycin, $2 \mathrm{~g} / \mathrm{L}$; and metronidazole, $2 \mathrm{~g} / \mathrm{L}$ ); Bifidobacterium. was $10^{9} \mathrm{CFU}$.

intestinal mucous membrane surface, forming biological barrier, constituting intestinal engraftment resistance to prevent bacterial pathogens, invading conditionally pathogenic bacteria, avoiding the occurrence of diseases and safeguarding the intestinal normal metabolism [4347]. Bifidobacteria, a commensal microorganism found in the gastrointestinal tract, has been proved as the core of the intestinal flora, contributing a lot to human health [48, 49]. Long-term studies have shown that the abundance of bifidobacteria is higher in individuals who are healthy and have greater longevity than the ordinary, and they exist throughout the lifetime [50]. Several strains have been attributed beneficial traits at local and systemic levels, through pathogen exclusion or immune modulation, among other benefits [51]. This study found that the polysaccharides could significantly increase the abundance of Bifidobacterium (Figure 9) in the cecum contents and reduce the levels of LPS, which were mainly secreted by Bacteroides spp., B. vulgatus, and Desulfovibrio spp., in serum and inflammation (Figure 7B and 7C).

The importance of human gut microbiome in health and disease has been recognized for decades. Increasing evidence indicated that altered intestinal microbial composition and function resulted in an increased risk of IBD [52]. Previous studies showed that diet resulted in significant changes in the composition of the cecal and fecal microbiota, and found diet-dependent shifts among the dominant bacterial phyla in the intestine of mice [18, 
53-55]. In humans, diet also modulated the intestinal microbiota [56-59]. Findings from many laboratories have shown that the composition and products of the gut microbiota have unexpected effects on immune and inflammatory responses $[17,60,61]$, and the genes that are also believed to be involved in IBD are usually involved in immune responses, transport, or bacterial recognition [62]. By changing gut microbiota, cancer incidence can be also change, IBD is the important induced factor for malignant gastrointestinal tumor $[63,64]$. In this study, the TNBS could significantly reduce the OTUs of the gut microbiota in rats $(P<0.05$ vs the normal group), as shown in Figure 5 , while treatment with $H$. erinaceus extracts recovered the number of OTUs to near normal, especially in the AEtreated groups $(P<0.05$ vs the TNBS-induced group, $P$ $>0.05$ vs the normal group) and ameliorated the clinical parameters of the IBD rats. All these results indicated that $H$. erinaceus had a potential to naturally improve the structure of gut microbiota/ immunomodulatory property and could be used as a drug or functional food ingredient for IBD or other gastrointestinal bacterial infections. The active ingredients and mode of action of H. erinaceus for IBD prevention and treatment are shown in Figure 11. The AE containing fatty acids and erinacines (3-hydroxyhericenone $\mathrm{F}$, hericenone $\mathrm{G}$, hericenone $\mathrm{F}$, and hericerin, ect) have antimicrobial and wound-healing properties, which can directly inhibit pathogen and repair the wound. The polysaccharides maninly influence the structure of the gut microbiota as polysaccharides for essential nutrients, and the small molecular organic acids produced from gut microbiota have many biological activities [65] but still need much more studies.

\section{MATERIALS AND METHODS}

\section{Preparation of the $\boldsymbol{H}$. erinaceus extracts}

The whole fruiting bodies of $H$. erinaceus (commoditized strain) were collected from the Research Laboratory of Edible Mushrooms of Guangdong Institute of Microbiology, China, in May 2015, and identified by Prof. Xie Yizhen of Guangdong Institute of Microbiology using shape features and ITS sequences. They were dried at $60^{\circ} \mathrm{C}$, ground into a fine powder, and averaged into two equal parts.

Ten parts of alcohol were added to one half of the aforementioned powdered substance and then refluxed for $1 \mathrm{~h}$ twice. The filtrate was merged and concentrated to dry at a low pressure using rotary evaporators. The residue collected was the $\mathrm{AE}$, which was stored at $4^{\circ} \mathrm{C}$ and prepared as oral suspension with distilled water for further use. Then, eight parts of distilled water was added to the alcohol-extracted residue, soaked for $2 \mathrm{~h}$, and refluxed for $1 \mathrm{~h}$ twice. The filtrate was merged and concentrated to $1 \mathrm{~g} / \mathrm{mL}$ (equivalent to the crude drugs) at a low pressure using rotary evaporators. When the solution cooled to $45^{\circ} \mathrm{C}$, the $\mathrm{pH}$ value was adjusted to 6.0 using diluted hydrochloric acid. The solution was then allowed to traverse through the ion exchange resin (D-900; Hebei Cangzhou Baoen Adsorption Materials Technology Co., Ltd, Hebei, China) at a speed of $1.0 \mathrm{Bv} / \mathrm{h}$ two times. The eluent was then concentrated to a low volume, cooled to room temperature, added to alcohol to a concentration of $80 \%$, and refrigerated at $4^{\circ} \mathrm{C}$ for $48 \mathrm{~h}$. The precipitation collected was the PE, which was stored at $4{ }^{\circ} \mathrm{C}$ and prepared as oral suspension with distilled water for further use.

Ten parts of 50\% aqueous alcohol (v/v) was added to the other half of the powdered substance and refluxed for $1 \mathrm{~h}$ twice. The filtrate was merged and concentrated to dry at a low pressure using rotary evaporators. The residue collected was the WE, which was re-suspended in distilled water and stored at $4{ }^{\circ} \mathrm{C}$ for further use.

\section{Animals and treatments}

Thirty adult male Sprague-Dawley rats (weight $180-220 \mathrm{~g})$ and ninety male Kunming mice (18-22 g) were purchased from the animal center of the Guangdong Medical Laboratory Animal Center, Guangzhou, China. The animals were kept in the specific-pathogen-free laboratory of Guangdong Laboratory Animals Monitoring Institute. The rats were kept in cages with three rats per cage $\left(30 \times 30 \times 20 \mathrm{~cm}^{3}\right)$ in a temperature $\left(22^{\circ} \mathrm{C} \pm 1{ }^{\circ} \mathrm{C}\right)$ and humidity $(55 \% \pm 10 \%)$ controlled room on a 12 -h light/dark cycle (lights were switched off at 17:00 h). The experimental protocols were approved by the laboratory of Guangdong Laboratory Animals Monitoring Institute, and all experimental procedures conformed to the National Institutes of Health Guide for the Care and Use of Laboratory Animals. All efforts were made to minimize the number of animals used.

\section{Effects on TNBS-induced IBD rats}

After 7 days of adaptation period, the animals were randomly divided into five groups (six rats in each group, and three per cage): $100 \mathrm{mg} /(\mathrm{kg} \cdot$ day), $\mathrm{PE}$ group; $100 \mathrm{mg} /(\mathrm{kg} \cdot$ day), AE group; $100 \mathrm{mg} /(\mathrm{kg} \cdot$ day, WE group; model group; and normal group, and more details showed in Table 1. The rats were fed a standard diet with free access to water. After $24 \mathrm{~h}$ of fasting, the rats were anesthesized using an intraperitoneal injection of $2 \%$ sodium pentobarbital $(0.2 \mathrm{~mL} / 100 \mathrm{~g})$. They were intubated (using latex tubing of $2 \mathrm{~mm}$ diameter, lubricated with edible oil) through the anus, and gently pushed into the lumen to about $8.0 \mathrm{~cm}$. Then, $150 \mathrm{mg} / \mathrm{kg}$ of TNBS (Sigma-Aldrich, MO, USA; dissolved in 50\% ethanol) solution was injected through the latex tubing. The rats were hung upside-down for $30 \mathrm{~s}$ to ensure that the mixture fully seeped into the lumen without leakage. The $H$. erinaceus extracts were administered intragastrically to the TNBS-induced animals after 1 day and last 2 weeks. 


\section{Effects on TNBS-induced IBD mice}

All mice were randomly divided into nine groups $(n=9)$ : control, model, model and high-dose antibiotics, polysaccharides $[100 \mathrm{mg} /(\mathrm{kg} \cdot \mathrm{d})]$, Bifidobacterium, polysaccharides plus high-dose antibiotics, polysaccharides plus Bifidobacterium, Bifidobacterium plus high-dose antibiotics, and polysaccharides plus Bifidobacterium plus high-dose antibiotics. All the antibiotics (ampicillin, $2 \mathrm{~g} / \mathrm{L}$; vancomycin, $1.0 \mathrm{~g} / \mathrm{L}$; neomycin, $2 \mathrm{~g} / \mathrm{L}$; and metronidazole, $2 \mathrm{~g} / \mathrm{L}$ ) were given for 7 days, then IBD was induced with a TNBS (150 mg/kg) enema, and more details showed in Table 2. After 7 days of drug treatment, the mice were induced again with TNBS enema, followed by another 4 days of drug treatment.

After treatment, the mice were anesthesized by an intraperitoneal injection of $2 \%$ sodium pentobarbital $(0.25$ $\mathrm{mL} / 100 \mathrm{~g}$ ), and the blood plasma was collected by the abdominal aortic method and the serum by centrifugation (1500 rpm, $10 \mathrm{~min}$ ). Then, the serum was subjected to analysis to detect the production of cytokines GM-CSF, TNF- $\gamma$, IL-10, IL-12, IL-17 $\alpha$, IL-4, TNF- $\alpha$, and VGEF, and the levels of LPS. The colons and spleens obtained from the rats were fixed in $4 \%$ paraformaldehyde at $\mathrm{pH}$ 7.4 for further pathological observation, and the cecum contents were collected for 16s rRNA analysis.

\section{General status observations and colon visceral organ index assay}

The percentage weight loss, characteristics of the stool, and the presence of blood in the stool were recorded to derive a Disease Activity Index (DAI). The scoring criteria were performed by three persons, all blinded to the experimental groups before DAI scoring, as described in a previous study [66].

The weight of the colon of each rat or mouse was recorded, and then the colons were stored in $4 \%$ paraformaldehyde or frozen as soon as possible for further analysis. The colon index (the weight of the colon/the length of the colon) was calculated.

\section{Histopathological examinations}

Histological changes were evaluated by H\&E analysis and immunohistochemically stained sections. The colon samples were processed according to the protocols described in a previous study [67], as well as for immunohistochemical analysis of Foxp3, TNF- $\alpha$, IL-10, and NF-кB p65 (1:100).

\section{Gut microbiota analysis}

\section{Bacterial DNA isolation}

Fresh fecal samples were collected before the fasting of the rats and stored at $-80^{\circ} \mathrm{C}$. The total bacterial DNA was extracted from $0.25 \mathrm{~g}$ of the fecal sample using the repeated bead beating method described by Favier with modifications as described in a previous study [65].

\section{S rRNA gene sequencing}

Fresh fecal samples were collected before the fasting of the rats and stored at $-80^{\circ} \mathrm{C}$. Frozen microbial DNA isolated from mice cecal sample with total masses ranging from 1.2 to $20.0 \mathrm{ng}$ were stored at $-20^{\circ} \mathrm{C}$. The microbial communities of $\mathrm{V} 3$ and $\mathrm{V} 4$ region $16 \mathrm{~S}$ rRNA genes were amplified using the forward primer 5'-ACTCCTACGGGAGGCAGCA-3' and the reverse primer 5'-GGACTACHVGGGTWTCTAAT-3'. Each amplified product was concentrated via solidphase reversible immobilization and quantified by electrophoresis using an Agilent 2100 Bioanalyzer (Agilent). After quantification of DNA concentration using Nanodrop, each sample was diluted to a concentration of $1 \times 10^{9} \mathrm{~mol} / \mu \mathrm{L}$ in the Tris-EDTA buffer and pooled. Then, $20 \mu \mathrm{L}$ of the pooled mixture was used for sequencing with the Illumina MiSeq sequencing system according to the manufacturer's instructions. Raw pyrosequencing reads obtained from the sequencer were denoised using the Titanium PyroNoise software. The resulting pyrosequencing reads were analyzed by common analysis methods [67].

\section{Microbiota classification}

Raw pyrosequencing reads obtained from the sequencer were denoised using the Titanium PyroNoise software. The resulting pyrosequencing reads were analyzed as described in a previous study [67].

\section{Enzyme-linked immunosorbent assay}

After 14 days of treatment, the rats or mice were anesthetized using an intraperitoneal injection of $2 \%$ sodium pentobarbital $(0.25 \mathrm{~mL} / 100 \mathrm{~g})$, decapitated, and dissected. The blood plasma was collected by the abdominal aortic method and the serum by centrifugation (1500 rpm, $10 \mathrm{~min}$ ). Then, the serum was subjected to analysis for the production of cytokines interleukin (1L)-1 $\alpha, 1 \mathrm{~L}-2,1 \mathrm{~L}-8,1 \mathrm{~L}-10,1 \mathrm{~L}-11$, and IL-12; tumor necrosis factor (TNF)- $\gamma$ and TNF- $\alpha$; vascular endothelial growth factor (VGEF); human macrophage inflammatory protein-1 $\alpha$ (MIP- $\alpha)$; and macrophage colony-stimulating factor (M-CSF) and so on. All the assays were carried out according to the procedures recommended in the enzyme-linked immunosorbent assay kit (Shanghai Bogoo Biological Technology Co., Ltd, China) manual.

\section{Determination of the MPO activity}

The myeloperoxidase (MPO) colorimetric kit (Jiancheng Bioengineering Institute, China) was used to measure the MPO activity in colon tissue homogenates to evaluate the severity of UC using the thiobarbituric acid method. 


\section{Caco-2 cell culture}

Caco-2 cells (a human colonic cell line; ATCC, MD, USA) were cultured in the Dulbecco's modified Eagle medium supplemented with $12 \%$ fetal bovine serum (FBS) and passaged twice weekly. For analysis, $10^{6}$ cells were plated in 24-well plates in a medium containing $12 \%$ FBS at $37^{\circ} \mathrm{C}$ in an atmosphere of $5 \% \mathrm{CO}_{2}$ and relative humidity of $90 \%$ and allowed to rest for $24 \mathrm{~h}$. Confluent cultures were stimulated with $1 \mu \mathrm{g} / \mathrm{mL}$ TNF- $\alpha$ and $1 \mu \mathrm{g} / \mathrm{mL}$ LPS added to the medium. The cells were harvested after $24 \mathrm{~h}$.

\section{Statistical analysis}

All data were expressed as means plus standard deviations of at least three independent experiments. The significant differences between treatments were analyzed by one-way analysis of variance followed by Dunnett's test in order to detect inter-group differences. A difference was considered statistically significant if the $p$ value was less than 0.05. Statistical Package was used the SPSS (Abacus Concepts, CA, USA) and Prism 5 (GraphPad, CA, USA) software.

\section{Abbreviations}

HE, Hericium erinaceus; IBD, inflammatory bowel disease; TNBS, trinitro-benzene-sulfonic acid; MPO, myeloperoxidase; IL-10, interleukin-10; TNF, tumor necrosis factor; UC, ulcerative colitis; DAI, Disease Activity Index; H\&E, Hematoxylin and eosin; VGEF, vascular endothelial growth factor; MIP- $\alpha$, human macrophage inflammatory protein- $1 \alpha$; M-CSF, macrophage colony-stimulating factor; FBS, fetal bovine serum; OUT, operational taxonomic unit; $\mathrm{AE}$, alcoholic extracts.

\section{Author contributions}

Chen Diling, Yang Xin, Zheng Chaoqun, Yang Jian, Chenjun, Shuai Ou and Xie Yizhen conceived and designed the experiments. Chen Diling, Yang Xin, Zheng Chaoqun, and Yang Jian, Tang Xiaocui performed the experiments. Chen Diling, Yang Xin, Zheng Chaoqun, Shuai ou, and Chenjun analyzed the data. Chen Diling and Yang Xin wrote the paper and edited the manuscript. All authors read and approved the final manuscript.

\section{CONFLICTS OF INTEREST}

The authors declare no conflicts of interest.

\section{FUNDING}

This work was supported by financial grants from the China National Ministry of Science and Technology Plan Projects (2013BAD16B00), the Guangdong Science and Technology Plan Projects (2015A020211021, 2016A050502032), the Guangzhou Science and Technology Plan Projects (201504281708257), the Highlevel Leading Talent Introduction Program of GDAS (2016GDASRC-0102), Guangzhou Medical University Research Projects (2016C28) and Nanyue Microbial Talents Cultivation Fund of Guangdong Institute of Microbiology. All the authors would like to thank Personal Biothechnology CO., Ltd. ShangHai, China for providing the sequencing service.

\section{REFERENCES}

1. Singh D, Srivastava S, Pradhan M, Kanwar JR, Singh MR. Inflammatory bowel disease: pathogenesis, causative factors, issues, drug treatment strategies, and delivery approaches. Crit Rev Ther Drug Carrier Syst. 2015; $32: 181-214$

2. Burisch J, Munkholm P. The epidemiology of inflammatory bowel disease. Scand J Gastroenterol. 2015; 50:942-51.

3. Burisch J. Crohn's disease and ulcerative colitis. Occurrence, course and prognosis during the first year of disease in a European population-based inception cohort. Dan Med J. 2014; 61:B4778.

4. D'Incà R, Paccagnella $\mathrm{M}$, Cardin $\mathrm{R}$, Pathak $\mathrm{S}$, Baldo V, Giron MC, Sturniolo GC. 5-ASA colonic mucosal concentrations resulting from different pharmaceutical formulations in ulcerative colitis. World J Gastroenterol. 2013; 19:5665-5670.

5. Bennett AL, Munkholm P, Andrews JM. Tools for primary care management of inflammatory bowel disease: do they exist? World J Gastroenterol. 2015; 21:4457-4465.

6. Hayek AJ, Pfanner TP, White HD. Inflammatory bowel disease of the lung: The role of infliximab? Respir Med Case Rep. 2015; 15:85-88.

7. Lobatón T, Ferrante M, Rutgeerts P, Ballet V, Van Assche $\mathrm{G}$, Vermeire S. Efficacy and safety of anti-TNF therapy in elderly patients with inflammatory bowel disease. Aliment Pharmacol Ther. 2015; 42:441-451.

8. Walker AW, Sanderson JD, Churcher C, Parkes GC, Hudspith BN, Rayment N, Brostoff J, Parkhill J, Dougan G, Petrovska L. High-throughput clone library analysis of the mucosa-associated microbiota reveals dysbiosis and differences between inflamed and non-inflamed regions of the intestine in inflammatory bowel disease. BMC Microbiol. 2011; 11:7.

9. Lepage P, Häsler R, Spehlmann ME, Rehman A, Zvirbliene A, Begun A, Ott S, Kupcinskas L, Doré J, Raedler A, Schreiber S. Twin study indicates loss of interaction between microbiota and mucosa of patients with ulcerative colitis. Gastroenterology. 2011; 141:227-236.

10. Tojo R, Suárez A, Clemente MG, de los Reyes-Gavilán CG, Margolles A, Gueimonde M, Ruas-Madiedo P. Intestinal 
microbiota in health and disease: role of bifidobacteria in gut homeostasis. World J Gastroenterol. 2014; 20:15163-15176.

11. McClure R, Massari P. TLR-dependent human mucosal epithelial cell responses to microbial pathogens. Front Immunol. 2014; 5:386.

12. Grasa L, Abecia L, Forcén R, Castro M, de Jalón JA, Latorre E, Alcalde AI, Murillo MD. Antibiotic-induced depletion of murine microbiota induces mild inflammation and changes in Toll-Like receptor patterns and intestinal motility. Microb Ecol. 2015; 70:835-848.

13. Rogier R, Koenders MI, Abdollahi-Roodsaz S. Tolllike receptor mediated modulation of $\mathrm{T}$ cell response by commensal intestinal microbiota as a trigger for autoimmune arthritis. J Immunol Res. 2015; 2015:527696.

14. Round JL, Mazmanian SK. The gut microbiota shapes intestinal immune responses during health and disease. Nat Rev Immunol. 2009; 9:313-323.

15. Sanders ME, Guarner F, Guerrant R, Holt PR, Quigley EM, Sartor RB, Sherman PM, Mayer EA. An update on the use and investigation of probiotics in health and disease. Gut. 2013; 62:787-796.

16. De Filippo C, Cavalieri D, Di Paola M, Ramazzotti M, Poullet JB, Massart S, Collini S, Pieraccini G, Lionetti P. Impact of diet in shaping gut microbiota revealed by a comparative study in children from Europe and rural Africa. Proc Natl Acad Sci USA. 2010; 107:14691-14696.

17. Maslowski KM, Vieira AT, Ng A, Kranich J, Sierro F, Yu D, Schilter HC, Rolph MS, Mackay F, Artis D, Xavier RJ, Teixeira MM, Mackay CR. Regulation of inflammatory responses by gut microbiota and chemoattractant receptor GPR43. Nature. 2009; 461:1282-1286.

18. Roca-Saavedra P, Mendez-Vilabrille V, Miranda JM, Nebot C, Cardelle-Cobas A, Franco CM, Cepeda A. Food additives contaminants and other minor components: effects on human gut microbiota-a review. J Physiol Biochem. 2017 May 9. https://doi.org/10.1007/s13105-017-0564-2.

19. Neuman MG, Nanau RM. Inflammatory bowel disease: role of diet, microbiota, life style. Transl Res. 2012; 160:29-44.

20. Elbatrawy EN, Ghonimy EA, Alassar MM, Wu FS. Medicinal mushroom extracts possess differential antioxidant activity and cytotoxicity to cancer cells. Int J Med Mushrooms. 2015; 17:471-479.

21. Friedman M. Antibiotic-resistant bacteria: prevalence in food and inactivation by food-compatible compounds and plant extracts. J Agric Food Chem. 2015; 63:3805-3822.

22. Li JL, Lu L, Dai CC, Chen K, Qiu JY. A comparative study on sterols of ethanol extract and water extract from Hericium erinaceus. [Article in Chinese] Zhongguo Zhong Yao Za Zhi. 2001; 26:831-34.

23. Kawagishi H, Masui A, Tokuyama S, Nakamura T. Erinacines $\mathrm{J}$ and $\mathrm{K}$ from the mycelia of Hericium erinaceum. Tetrahedron. 2006; 62:8463-8466.

24. Kim SP, Moon E, Nam SH, Friedman M. Hericium erinaceus mushroom extracts protect infected mice against
Salmonella Typhimurium-induced liver damage and mortality by stimulation of innate immune cells. J Agric Food Chem. 2012; 60:5590-5596.

25. Friedman M, Rasooly R. Review of the inhibition of biological activities of food-related selected toxins by natural compounds. Toxins (Basel). 2013; 5:743-775.

26. Wong KH, Sabaratnam V, Abdullah N, Kuppusamy UR, Naidu M. Effects of cultivation techniques and processing on antimicrobial and antioxidant activities of Hericium erinaceus (Bull.:Fr.) Pers extracts. Food Technol Biotechnol. 2009; 47: 47-55.

27. Shang X, Tan Q, Liu R, Yu K, Li P, Zhao GP. In vitro antiHelicobacter pylori effects of medicinal mushroom extracts, with special emphasis on the Lion's Mane mushroom, Hericium erinaceus (higher Basidiomycetes). Int J Med Mushrooms. 2013; 15:165-74.

28. Zhu Y, Chen Y, Li Q, Zhao T, Zhang M, Feng W, Takase M, Wu X, Zhou Z, Yang L, Wu X. Preparation, characterization, and anti-Helicobacter pylori activity of $\mathrm{Bi}^{3+}$-Hericium erinaceus polysaccharide complex. Carbohydr Polym. 2014; 110:231-237.

29. Mikocka-Walus A, Andrews JM, Rampton D, Goodhand $\mathrm{J}$, van der Woude J, Bernstein CN. How can we improve models of care in inflammatory bowel disease? An international survey of IBD health professionals. J Crohn's Colitis. 2014; 8:1668-1674.

30. Khanna PV, Shih DQ, Haritunians T, McGovern DP, Targan $\mathrm{S}$. Use of animal models in elucidating disease pathogenesis in IBD. Semin Immunopathol. 2014; 36:541-551.

31. Rapalli A, Bertoni S, Arcaro V, Saccani F, Grandi A, Vivo V, Cantoni AM, Barocelli E. Dual role of endogenous serotonin in 2,4,6-trinitrobenzene sulfonic acid-induced colitis. Front Pharmacol. 2016; 7:68.

32. Liu TC, Gurram B, Baldridge M, Head R, Lam V, Luo C, Cao Y, Simpson P, Hayward M, Holtz M, Noe J, Lerner D, Cabrera J, et al. O-011 Paneth cell phenotypes define a subtype of pediatric Crohn's disease through alterations in host-microbial interactions. Inflamm Bowel Dis. 2016; 22 Suppl 1:S4.

33. Hoffmann TW, Pham HP, Bridonneau C, Aubry C, Lamas B, Martin-Gallausiaux C, Moroldo M, Rainteau D, Lapaque N, Six A, Richard ML, Fargier E, Le Guern ME, et al. Microorganisms linked to inflammatory bowel diseaseassociated dysbiosis differentially impact host physiology in gnotobiotic mice. ISME J. 2016; 10:460-477.

34. Torres J, Bao X, Goel A, Colombel JF, Pekow J, Jabri B, Williams KM, Castillo A, Odin JA, Meckel K, Fasihuddin F, Peter I, Itzkowitz S, Hu J. The features of mucosaassociated microbiota in primary sclerosing cholangitis. Aliment Pharmacol Ther. 2016; 43:790-801.

35. Rizzo G, Pugliese D, Armuzzi A, Coco C. Anti-TNF alpha in the treatment of ulcerative colitis: a valid approach for organ-sparing or an expensive option to delay surgery? World J Gastroenterol. 2014; 20:4839-4845. 
36. Guerra GC, Araújo AA, Lira GA, Melo MN, Souto KK, Fernandes D, Silva AL, Araújo Júnior RF. Telmisartan decreases inflammation by modulating TNF- $\alpha$, IL-10, and RANK/RANKL in a rat model of ulcerative colitis. Pharmacol Rep. 2015; 67:520-526.

37. Yamada A, Arakaki R, Saito M, Tsunematsu T, Kudo Y, Ishimaru N. Role of regulatory $\mathrm{T}$ cell in the pathogenesis of inflammatory bowel disease. World J Gastroenterol. 2016; 22:2195-2205.

38. Li Z, Arijs I, De Hertogh G, Vermeire S, Noman M, Bullens D, Coorevits L, Sagaert X, Schuit F, Rutgeerts P, Ceuppens JL, Van Assche G. Reciprocal changes of Foxp3 expression in blood and intestinal mucosa in IBD patients responding to infliximab. Inflamm Bowel Dis. 2010; 16:1299-310.

39. Chu H, Khosravi A, Kusumawardhani IP, Kwon AH, Vasconcelos AC, Cunha LD, Mayer AE, Shen Y, Wu WL, Kambal A, Targan SR, Xavier RJ, Ernst PB, et al. Genemicrobiota $\mathrm{tt}$ inflammatory bowel disease. Science. 2016; 352:1116-20.

40. Haghikia A, Jörg S, Duscha A, Berg J, Manzel A, Waschbisch A, Hammer A, Lee DH, May C, Wilck N, Balogh A, Ostermann AI, Schebb NH, et al. Dietary fatty acids directly impact central nervous system autoimmunityviathe small intestine. Immunity. 2015; 43:817-829.

41. Khan MA, Tania M, Liu R, Rahman MM. Hericium erinaceus: an edible mushroom with medicinal values. J Complement Integr Med. 2013; 10:1-6.

42. Li W, Zhou W, Song SB, Shim SH, Kim YH. Sterol fatty acid esters from the mushroom Hericium erinaceum and their PPAR transactivational effects. J Nat Prod. 2014; 77:2611-2618.

43. Qiao YQ, Cai CW, Ran ZH. Therapeutic Modulation of the gut microbiota in IBD - more questions to be answered. J Dig Dis. 2016; 17:800-810.

44. Hashemi A, Villa CR, Comelli EM. Probiotics in early life: a preventative and treatment approach. Food Funct. 2016; 7:1752-1768.

45. Thomas LV, Suzuki K, Zhao J. Probiotics: a proactive approach to health. A symposium report. Br J Nutr. 2015 (Suppl 1); 114:S1-15.

46. Robles Alonso V, Guarner F. Linking the gut microbiota to human health. Br J Nutr. 2013 (Suppl 2); 109:S21-26.

47. Duncan SH, Flint HJ. Probiotics and prebiotics and health in ageing populations. Maturitas. 2013; 75:44-50.

48. Turroni F, Ventura M, Buttó LF, Duranti S, O'Toole PW, Motherway MO, van Sinderen D. Molecular dialogue between the human gut microbiota and the host: a Lactobacillus and Bifidobacterium perspective. Cell Mol Life Sci. 2014; 71:183-203.

49. Kleerebezem M, Vaughan EE. Probiotic and gut lactobacilli and bifidobacteria: molecular approaches to study diversity and activity. Annu Rev Microbiol. 2009; 63:269-290.
50. Bezirtzoglou E, Stavropoulou E. Immunology and probiotic impact of the newborn and young children intestinal microflora. Anaerobe. 2011;17:369-374.

51. Cunningham-Rundles S, Ahrné S, Johann-Liang R, Abuav R, Dunn-Navarra AM, Grassey C, Bengmark S, Cervia JS. Effect of probiotic bacteria on microbial host defense, growth, and immune function in human immunodeficiency virus type-1 infection. Nutrients. 2011; 3:1042-1070.

52. Rehman A, Rausch P, Wang J, Skieceviciene J, Kiudelis G, Bhagalia K, Amarapurkar D, Kupcinskas L, Schreiber S, Rosenstiel P, Baines JF, Ott S. Geographical patterns of the standing and active human gut microbiome in health and IBD. Gut. 2016; 65:238-48.

53. Turnbaugh PJ, Ridaura VK, Faith JJ, Rey FE, Knight R, Gordon JI. The effect of diet on the human gut microbiome: a metagenomic analysis in humanized gnotobiotic mice. Sci Transl Med. 2009; 1:6ra14.

54. Ravussin Y, Koren O, Spor A, LeDuc C, Gutman R, Stombaugh J, Knight R, Ley RE, Leibel RL. Responses of gut microbiota to diet composition and weight loss in lean and obese mice. Obesity (Silver Spring). 2012; 20:738-747.

55. Kashyap PC, Marcobal A, Ursell LK, Larauche M, Duboc H, Earle KA, Sonnenburg ED, Ferreyra JA, Higginbottom SK, Million M, Tache Y, Pasricha PJ, Knight R, et al. Complex interactions among diet, gastrointestinal transit, and gut microbiota in humanized mice. Gastroenterology. 2013; 144:967-977.

56. Wu GD, Chen J, Hoffmann C, Bittinger K, Chen YY, Keilbaugh SA, Bewtra M, Knights D, Walters WA, Knight R, Sinha R, Gilroy E, Gupta K, et al. Linking long-term dietary patterns with gut microbial enterotypes. Science. 2011; 334:105-108.

57. Cotillard A, Kennedy SP, Kong LC, Prifti E, Pons N, Le Chatelier E, Almeida M, Quinquis B, Levenez F, Galleron $\mathrm{N}$, Gougis S, Rizkalla S, Batto JM, et al, and ANR MicroObes consortium. Dietary intervention impact on gut microbial gene richness. Nature. 2013; 500:585-588.

58. Smith MI, Yatsunenko T, Manary MJ, Trehan I, Mkakosya R, Cheng J, Kau AL, Rich SS, Concannon P, Mychaleckyj JC, Liu J, Houpt E, Li JV, et al. Gut microbiomes of Malawian twin pairs discordant for kwashiorkor. Science. 2013; 339:548-554.

59. Lukens JR, Gurung P, Vogel P, Johnson GR, Carter RA, McGoldrick DJ, Bandi SR, Calabrese CR, Vande Walle L, Lamkanfi M, Kanneganti TD. Dietary modulation of the microbiome affects autoinflammatory disease. Nature. 2014; 516:246-249.

60. Wen L, Ley RE, Volchkov PY, Stranges PB, Avanesyan L, Stonebraker AC, Hu C, Wong FS, Szot GL, Bluestone JA, Gordon JI, Chervonsky AV. Innate immunity and intestinal microbiota in the development of Type 1 diabetes. Nature. 2008; 455:1109-1013.

61. Clarke TB, Davis KM, Lysenko ES, Zhou AY, Yu Y, Weiser JN. Recognition of peptidoglycan from the microbiota 
by Nod1 enhances systemic innate immunity. Nat Med. 2010;16:228-231.

62. Cho JH. The genetics and immunopathogenesis of inflammatory bowel disease. Nat Rev Immunol. 2008; 8:458-466.

63. Isik A, Soyturk M, Süleyman S, Firat D, Peker K, Yilmaz İ, Celebi F. Correlation of bowel wall thickening seen using computerized tomography with colonoscopies: a preliminary study. Surg Laparosc Endosc Percutan Tech. 2017; 27:154-157.

64. Isik A, Gursul C, Peker K, Aydın M, Firat D, Y1lmaz İ. Metalloproteinases and their inhibitors in patients with inguinal hernia. World J Surg. 2017; 41:1259-1266.
65. De Preter V, Machiels K, Joossens M, Arijs I, Matthys C, Vermeire S, Rutgeerts P, Verbeke K. Faecal metabolite profiling identifies medium-chain fatty acids as discriminating compounds in IBD. Gut. 2015; 64:447-58.

66. Tang Y, Chen Y, Wang X, Song G, Li Y, Shi L. Combinatorial intervention with mesenchymal stem cells and granulocyte colony-stimulating factor in a rat model of ulcerative colitis. Dig Dis Sci. 2015; 60:1948-1957.

67. Ling Z, Liu X, Jia X, Cheng Y, Luo Y, Yuan L, Wang Y, Zhao C, Guo S, Li L, Xu X, Xiang C. Impacts of infection with different toxigenic Clostridium difficile strains on faecal microbiota in children. Sci Rep. 2014; 4:7485. 